Prepared for the U. S. Department of Energy

under Contract DE-AC05-76RL01830

\title{
NV Energy Solar Integration Study: Cycling and Movements of Conventional Generators for Balancing Services
}
R. Diao
S. Lu
P. Etingov
Y. V. Makarov
J. Ma
X. Guo

July 2011 


\title{
DISCLAIMER
}

This report was prepared as an account of work sponsored by an agency of the United States Government. Neither the United States Government nor any agency thereof, nor Battelle Memorial Institute, nor any of their employees, makes any warranty, express or implied, or assumes any legal liability or responsibility for the accuracy, completeness, or usefulness of any information, apparatus, product, or process disclosed, or represents that its use would not infringe privately owned rights. Reference herein to any specific commercial product, process, or service by trade name, trademark, manufacturer, or otherwise does not necessarily constitute or imply its endorsement, recommendation, or favoring by the United States Government or any agency thereof, or Battelle Memorial Institute. The views and opinions of authors expressed herein do not necessarily state or reflect those of the United States Government or any agency thereof.

\author{
PACIFIC NORTHWEST NATIONAL LABORATORY \\ operated by \\ BATTELLE \\ for the \\ UNITED STATES DEPARTMENT OF ENERGY \\ under Contract DE-AC05-76RL01830
}

Printed in the United States of America

\author{
Available to DOE and DOE contractors from the Office of Scientific and Technical \\ Information, \\ P.O. Box 62, Oak Ridge, TN 37831-0062; ph: (865) 576-8401 fax: (865) 576-5728 email: \\ reports@adonis.osti.gov
}

\begin{abstract}
Available to the public from the National Technical Information Service, U.S. Department of Commerce, 5285 Port Royal Rd., Springfield, VA 22161 ph: (800) 553-6847 fax: (703) 605-6900

email: orders@ntis.fedworld.gov online ordering: http://www.ntis.gov/ordering.htm
\end{abstract}

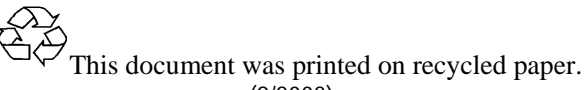

$(9 / 2003)$ 


\title{
NV Energy Solar Integration Study: Cycling and Movements of Conventional Generators for Balancing Services
}

\author{
R. Diao (Task Lead) S. Lu (Principle Investigator) \\ P. Etingov \\ Y. V. Makarov \\ J. Ma \\ X. Guo
}

July 2011

Prepared for

the U. S. Department of Energy

under Contract DE-AC05-76RL01830

Pacific Northwest National Laboratory

Richland, Washington 99352 


\begin{abstract}
With an increasing penetration level of solar photovoltaic (PV) generation in the southern Nevada power system, the impact of solar on system operations needs to be carefully studied from mainly two perspectives: energy production and balancing services. On the energy production side, more startups and lower capacity factors on the conventional generators are anticipated, which can be quantified using production cost model simulations. On the balancing services side, it is expected that the balancing requirements to compensate for solar power variability will be larger in magnitude; meanwhile, generators providing load following and regulation services may also need to move up or down more frequently. This study develops two effective metrics to quantitatively evaluate the cycling and movements of conventional generators for providing balancing services at different levels of solar power penetration. The two metrics include (1) mileage and number of direction changes in balancing service (load following/regulation); and (2) ramp (or half-cycle) analysis. The results demonstrate a significant impact of increased solar capacity on balancing service provided by conventional generator movements. Busy hours of balancing requirements are also identified for different study cases, representing various solar penetration levels. This study provides a basis for evaluating the wear and tear of the conventional generators in the solar integration process in the Nevada power system.
\end{abstract}




\section{Acknowledgement}

The authors would like to thank NV Energy and the solar impact study team for their support and productive discussions. 


\section{Contents}

\begin{tabular}{|c|c|}
\hline & i \\
\hline 1.0 & 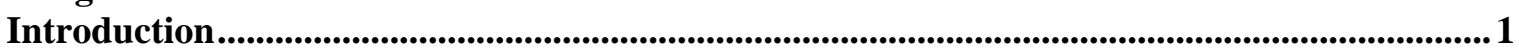 \\
\hline 1.1 & Background ... \\
\hline 1.2 & Objectives . \\
\hline 1.3 & Structure of the Report. \\
\hline 2.0 &  \\
\hline 2.1 & Mileage of Generator Movements for Regulation and Load Following ..................................... \\
\hline 2.2 & Service Ramp Statistics \\
\hline 3.0 &  \\
\hline 4.0 & 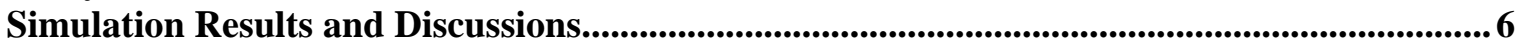 \\
\hline 4.1 & 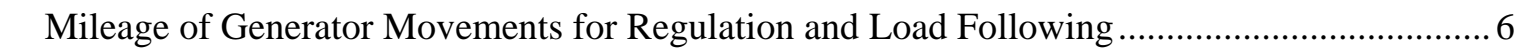 \\
\hline 4.2 & istics. \\
\hline 5.0 & 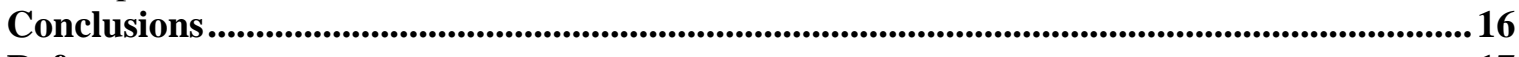 \\
\hline 6.0 & 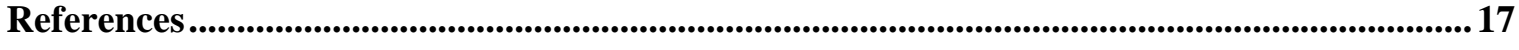 \\
\hline
\end{tabular}




\section{Figures}

Figure 2-1. Computing generator movement mileage and number of direction changes ....

Figure 2-2. Comparison of mileage and number of direction changes between cases with and without



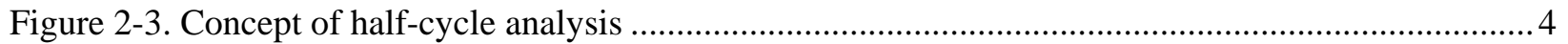

Figure 2-4. three-dimensional histogram for half cycles ...................................................................... 4

Figure 4-1. Daily average of direction changes and mileage for load following in Base Case and Case 5A6

Figure 4-2. Daily average of direction changes and mileage for regulation in Base Case and Case 5A ...... 7

Figure 4-3. Comparison of yearly load following mileage and direction changes with regard to large-scale

PV capacity (Study scenarios: Base Case, 1A, 2A, 3A, 4A, 5A) …...................................................... 8

Figure 4-4. Comparison of yearly load following mileage and direction changes with regard to DG capacity (Study scenarios: Base Case, 1A, 1B, 1C) ............................................................................. 8

Figure 4-5. Comparison of yearly regulation mileage and direction changes with regard to large-scale PV capacity (Study scenarios: Base Case, 1A, 2A, 3A, 4A, 5A) ............................................................. 9

Figure 4-6. Comparison of yearly regulation mileage and direction changes with regard to DG capacity .. 9 Figure 4-7. Comparison of average load following mileage and direction changes with regard to largescale PV capacity for operating hour 12 pm (study scenarios: Base Case, 1A, 2A, 3A, 4A, 5A) ............. 10 Figure 4-8. Comparison of average load following mileage and direction changes with regard to DG capacity for operating hour 12 pm (study scenarios: Base Case, 1A, 1B, 1C) ......................................... 10 Figure 4-9. Comparison of average regulation mileage and direction changes with regard to large-scale PV capacity for operating hour 12 pm (study scenarios: Base Case, 1A, 2A, 3A, 4A, 5A) ..................... 11 Figure 4-10. Comparison of average regulation mileage and direction changes with regard to DG capacity for operating hour 12 pm (study scenarios: Base Case, 1A, 1B, 1C)...................................................... 11 Figure 4-11. Comparison of average load following half-cycle magnitude with regard to large-scale PV capacity (Study scenarios: Base Case, 1A, 2A, 3A, 4A, 5A) …............................................................. 14 Figure 4-12. Comparison of average load following half-cycle magnitude with regard to DG capacity ... 14 Figure 4-13. Comparison of average regulation half-cycle magnitude with regard to large-scale PV capacity (Study scenarios: Base Case, 1A, 2A, 3A, 4A, 5A) ............................................................... 15 Figure 4-14. Comparison of average regulation half-cycle magnitude with regard to DG capacity .......... 15 


\section{Tables}

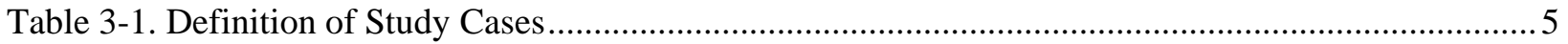

Table 4-1. Summary of linear fitted curves ............................................................................................. 12

Table 4-2. Load Following Half-cycle Analysis for Base Case............................................................. 12

Table 4-3. Load Following Half-cycle Analysis for Case 5A …............................................................. 12

Table 4-4. Regulation Half-cycle Analysis for Base Case.................................................................... 13



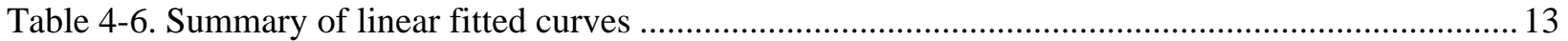




\subsection{Introduction}

\subsection{Background}

With an increasing penetration level of solar photovoltaic (PV) generation in the form of both utility scale and distributed generation (DG) in the southern Nevada system, the impact of solar on system operations needs to be carefully studied from mainly two perspectives: energy production and balancing services. On the energy production side, more startups and lower capacity factors on the conventional generators are anticipated, which can be quantified using production cost model simulations. On the balancing services side, it is expected that the balancing requirements to compensate for solar power variability will be larger in magnitude; meanwhile, generators providing load following and regulation services may also need to move up or down more frequently. The focus of this report is to quantitatively evaluate the cycling and movements of conventional generators for providing balancing services at different solar power penetration levels.

\subsection{Objectives}

This study is aimed at developing effective methodologies for the evaluation of conventional generator cycling and movements at different levels of large PV and DG penetration. The focus is generators providing balancing services, including regulation and load following, to compensate for the variability of load and solar PV. Two metrics are established in the report. The results provide a basis for evaluating the wear and tear of the conventional generators in the solar integration process.

\subsection{Structure of the Report}

The report is organized as follows: Section 2 explains the two proposed metrics to quantify generator cycling and movements; Section 3 describes the study cases including data requirements for different study scenarios; Section 4 shows the evaluation results; and Section 5 concludes the report. 


\subsection{Proposed Methodologies}

There are two metrics defined in this section, which includes (1) mileage and direction changes of balancing requirements (including load following and regulation) and (2) a three-dimensional histogram (ramp rate, ramp duration and occurring frequency) of load following/regulation half-cycles. Each of these metrics is described below.

\subsection{Mileage of Generator Movements for Regulation and Load Following}

The first metric is to compute total mileage travelled in MW and total number of direction changes that conventional generators need to do to balance the variable load and solar. This idea is illustrated in Figure 2-1, where the swinging door algorithm is applied to smooth the curve and identify the turning points. With the identified turning points on the balancing curve like load following requirement,

Total mileage of moving up = sum of all moving up curves (projection on the y axis)

Total mileage of moving down $=$ sum of all moving down curves (projection on the y axis)

Total number of direction changes $=$ number of turning points on the curve

Such computation will be performed for each operating hour throughout the entire study year. In this way, busy hours that require more balancing services and movements can be observed easily. For a particular period of time like a day or a month, the required mileage and number of direction changes can be accumulated for comparison between cases with different levels of solar penetration. An example of such comparison is given in Figure 2-2.

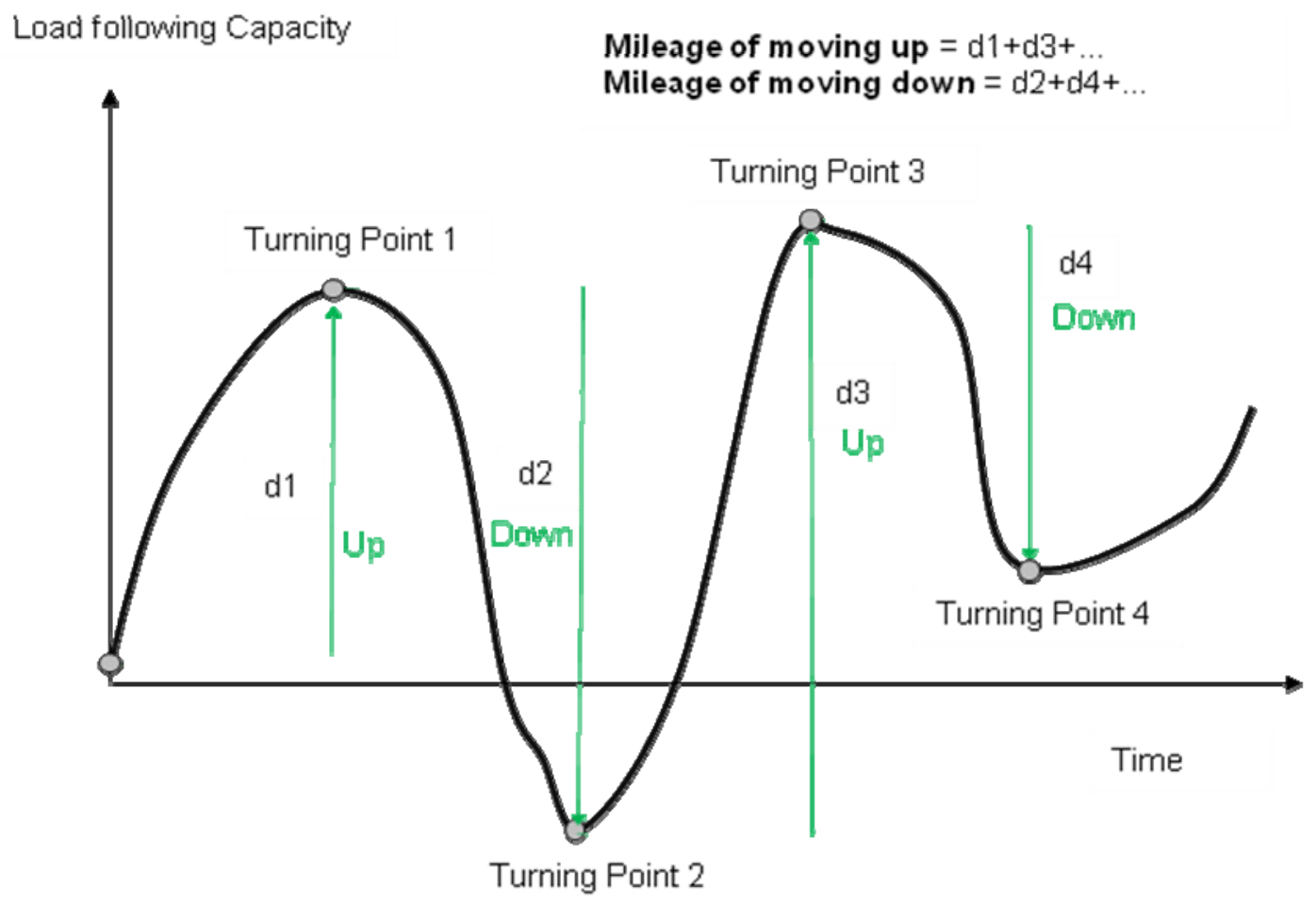

Figure 2-1. Computing generator movement mileage and number of direction changes 


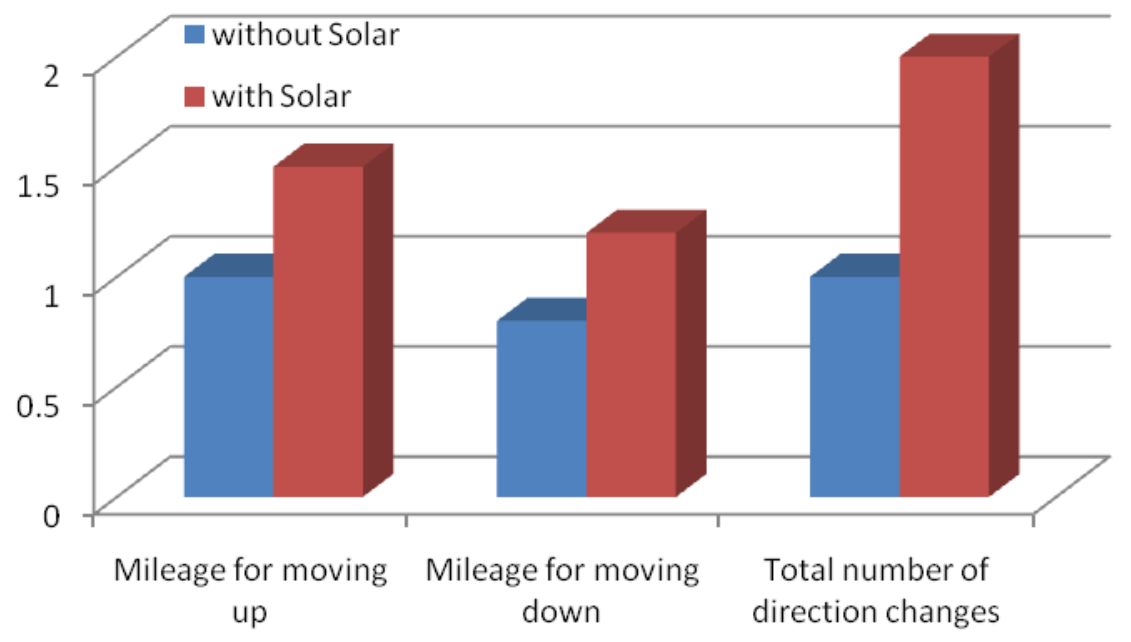

Figure 2-2. Comparison of mileage and number of direction changes between cases with and without solar

Data requirements:

1) Load following curves for different scenarios throughout the entire study year

2) Regulation curves for different scenarios throughout the entire study year

Algorithm:

1) Given a load following or regulation curve, apply the swinging door algorithm to smooth the curve

2) Identify the turning points in the curve throughout the year

3) For each operating hour,

a. Compute mileage_up, mileage_down and number of direction change

b. Compare different scenarios for 24 operating hours

4) Specify the time period to be studied, e.g., a day, a month or a year

a. Sum up all mileage for moving up

b. Sum up all mileage for moving down

c. Sum up total number of direction changes

d. Compare mileage up, mileage down and number of direction changes for all study scenarios.

\subsection{Balancing Service Ramp Statistics}

The second metric introduces the concept of half-cycle analysis, which can be used to evaluate and compare balancing requirements for different scenarios [1]. The idea of defining a half-cycle is similar to Metric 1 defined in Section 2.1. After identifying the turning points in load following/regulation curve, the magnitude between two adjacent turning points along the magnitude axis is defined as half-cycle magnitude (+/-). The distance between the two turning points along the time axis is the duration of each half-cycle, shown in Figure 2-3. Half-cycle ramp rate is then calculated as the ratio between half-cycle magnitude and half-cycle duration. A three-dimensional histogram with respect to duration and ramp rate can be generated for comparison, as shown in Figure 2-4. 


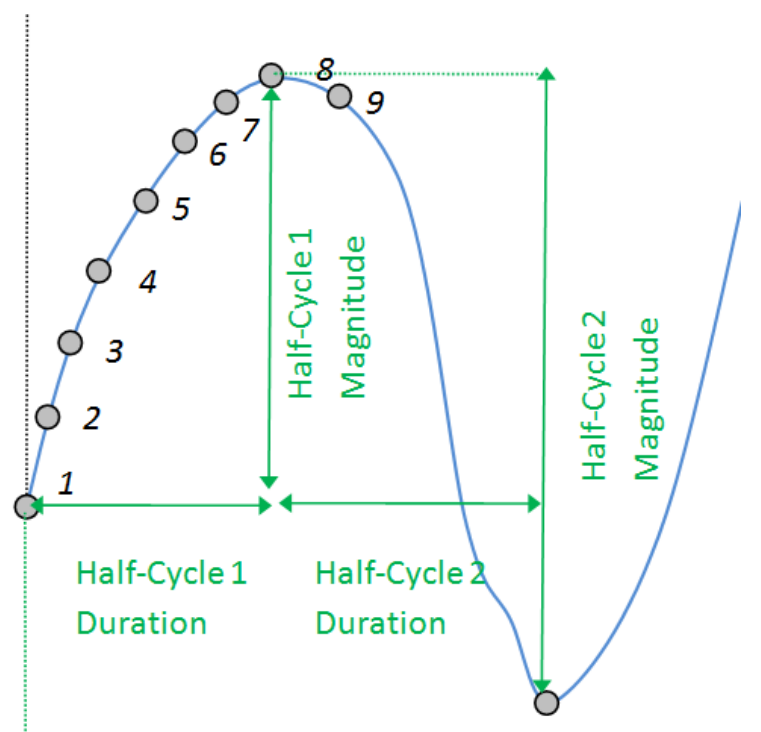

Figure 2-3. Concept of half-cycle analysis

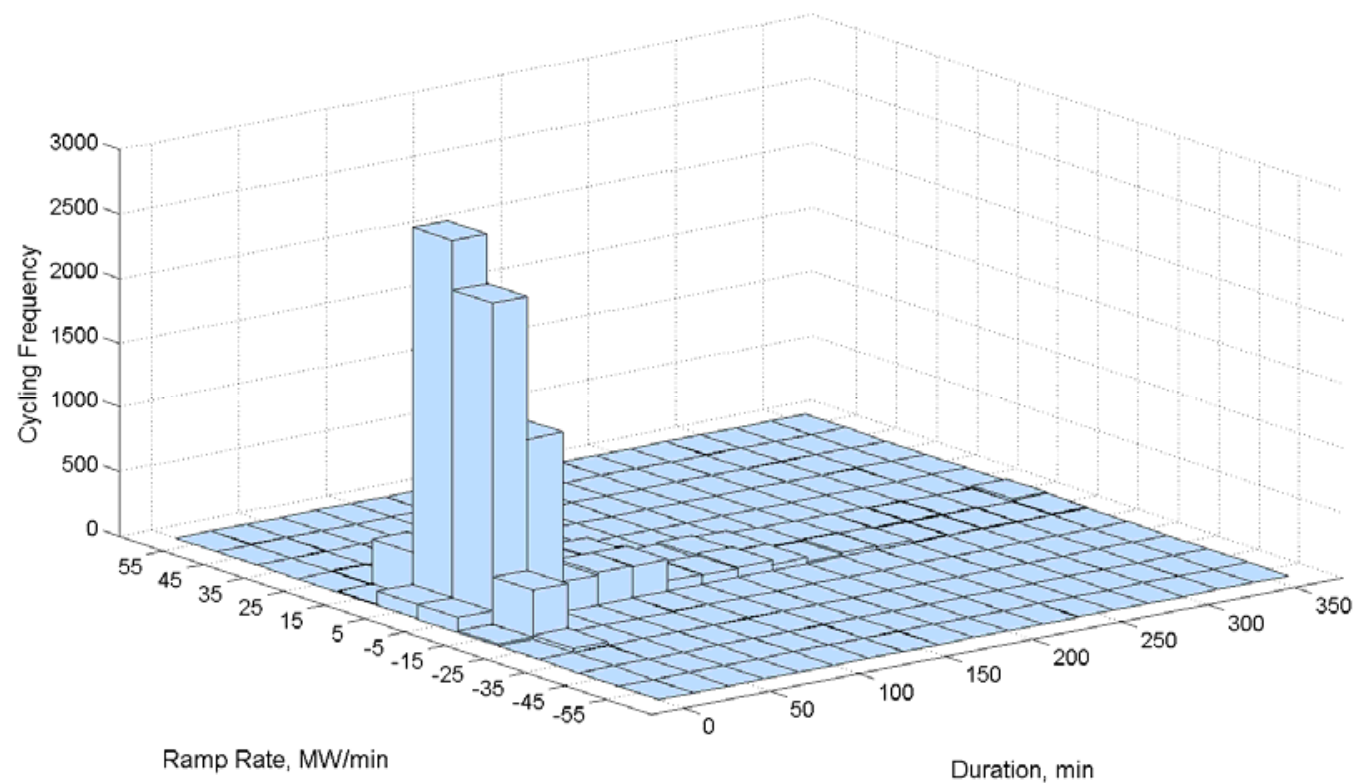

Figure 2-4. three-dimensional histogram for half cycles

Data requirements:

1) Load following curves for different scenarios throughout the entire study year

2) Regulation curves for different scenarios throughout the entire study year

Algorithm:

1) Given a load following/regulation curve, apply swinging door algorithm and identify turning points on the curve

2) Calculate half-cycle ramp rate and duration

3) Plot three-dimensional histograms for different scenarios using ramp rate and duration of half cycles 


\subsection{Study Scenarios}

A total of 11 solar penetration cases were defined based on various combinations of large-scale PV and DG. The difference between these cases is summarized in Table 3-1.

Table 3-1. Definition of Study Cases

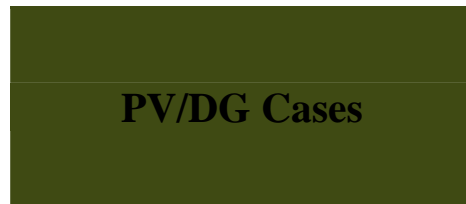

DG - Percent of Peak Load

0 MW

$1 \%(50 \mathrm{MW}) \quad 9 \%(450 \mathrm{MW}) 15 \%$ (750 MW)

Case 0 - 0 MW $\quad$ Base Case

Case 1 - 149 MW

1

$1 \mathrm{~A}$

1B

$1 \mathrm{C}$

Case 2 - $222 \mathrm{MW}$

2A

Large

PV

Case 3 - 292 MW

3A

3C

Case 4 - 492 MW

$4 \mathrm{~A}$

4B

Case 5 - 892 MW

$5 \mathrm{~A}$

Base case is a southern Nevada system behavior without any large PV or DG installations. All other cases include certain amount of large PV and DG.

Generation schedules of 54 units for the entire study year are also provided by Navigant through PROMOD simulations. Load following and regulation curves are calculated using PNNL's method [2, 3]. These data form the basis for computing the above metrics. 


\subsection{Simulation Results and Discussions}

This section discusses the simulation results obtained for the study cases defined in Section 3 using the proposed 2 metrics.

\subsection{Mileage of Generator Movements for Regulation and Load Following}

There are 10 cases studied in this section, including all cases defined in Table 3-1 but Case 1. Figure 4-1 compares the daily average mileages and direction changes required for load following in each operating hour, for Base Case and Case 5A. Figure 4-2 compares the same metrics but for regulation. Considering that generators do not need to move when load/generation mismatch is less than a certain threshold, regulation ramps with magnitudes less than $20 \mathrm{MW}$ were not counted. From the results, busy hours including morning peak, afternoon peak and midnight peak with more frequent and larger generator movements can be identified. By comparing both cases, a large increase in load following mileage and number of direction changes is observed from 3:00 pm to 5:00 pm (Figure 4-1); a significant increase in mileage of regulation from 8:00 am to 5:00 pm is observed for Case 5A (Figure 4-2). The simulation results for the other cases are given in Appendix A.
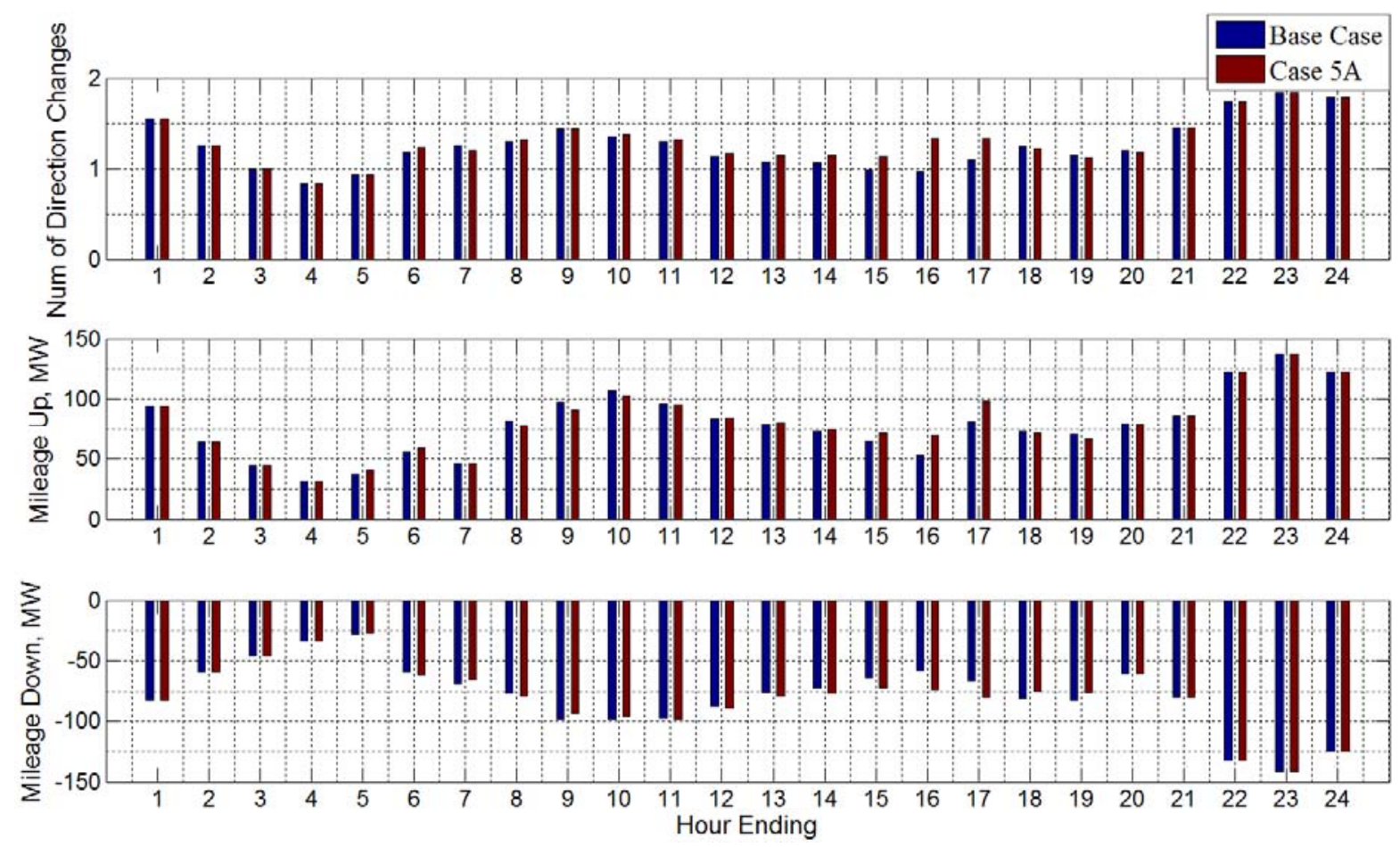

Figure 4-1. Daily average of direction changes and mileage for load following in Base Case and Case 5A 



Figure 4-2. Daily average of direction changes and mileage for regulation in Base Case and Case 5A

Figure 4-3 and Figure 4-4 depict the trend of the yearly accumulated load following mileages and number of direction changes with respect to large-scale PV and DG capacity, respectively. Linear curve fitting using least square method is used to approximate the simulated points in each trend plot, and the derived linear equations are also shown in the figures. Although we observe certain nonlinear behavior in the plots, linear curve fitting method can provide a simple and direct approximation of the relationship between installed PV/DG and the movement of conventional generators. Nonlinear curve fitting method can also be used to derive a more accurate relationship if necessary.

The slope of the fitted linear curve can provide important information regarding additional wear and tear cost caused by increased capacity of large-scale PV or DG. For example, an increase of $1 \mathrm{MW}$ in PV installed capacity can approximately cause 2.3 more direction changes and $240 \mathrm{MW}$ of mileage increase (both up and down) in load following process throughout the year, as shown in the three subplots of Figure 4-3. Similarly, an increase of $1 \mathrm{MW}$ in DG installed capacity can approximately cause 2.5 more direction changes and $300 \mathrm{MW}$ of mileage increase (both up and down) in load following process, as shown in Figure 4-4. It is clearly shown that more large-scale PV and DG generation will cause more load following mileages and direction changes, indicating that conventional generators need to move more frequently to balance the variable resources. 

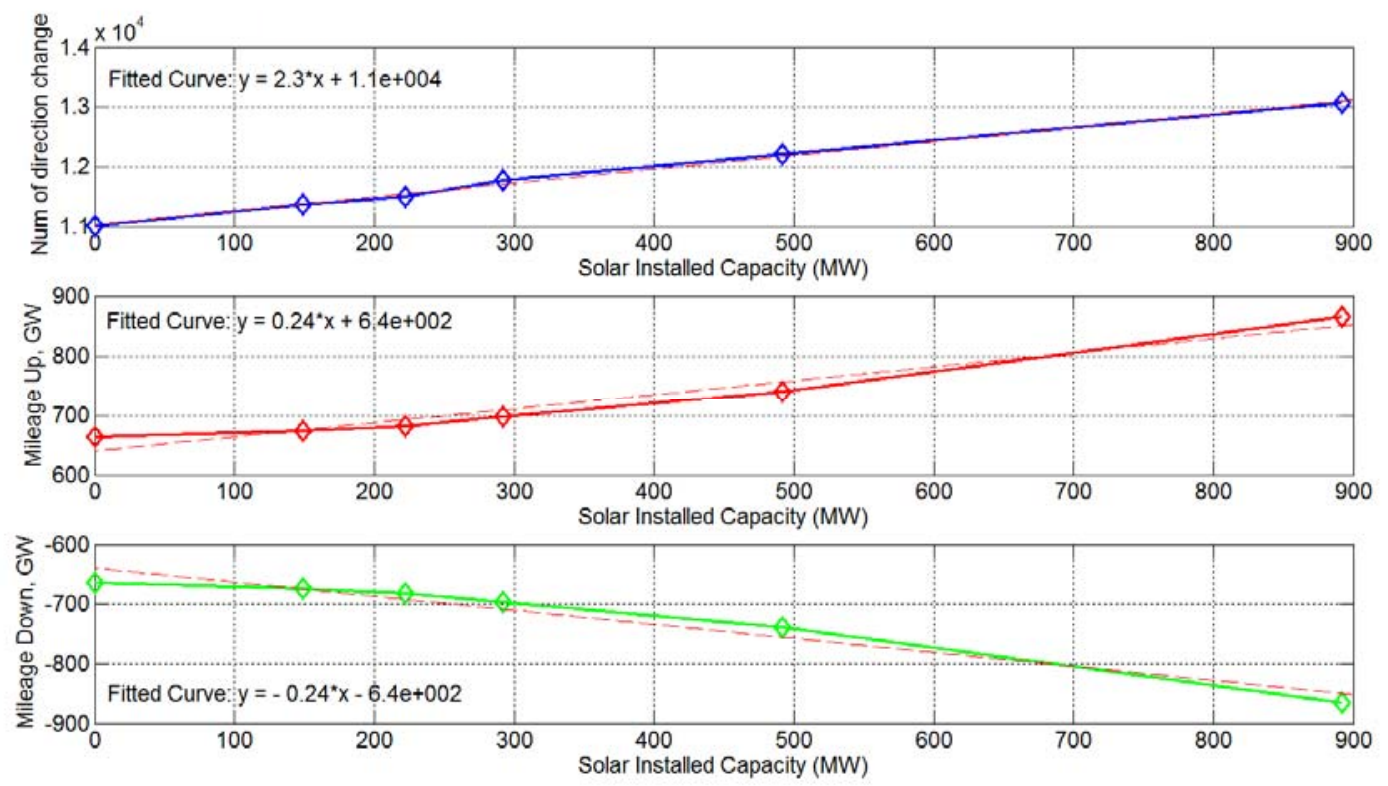

Figure 4-3. Comparison of yearly load following mileage and direction changes with regard to large-scale PV capacity (Study scenarios: Base Case, 1A, 2A, 3A, 4A, 5A)
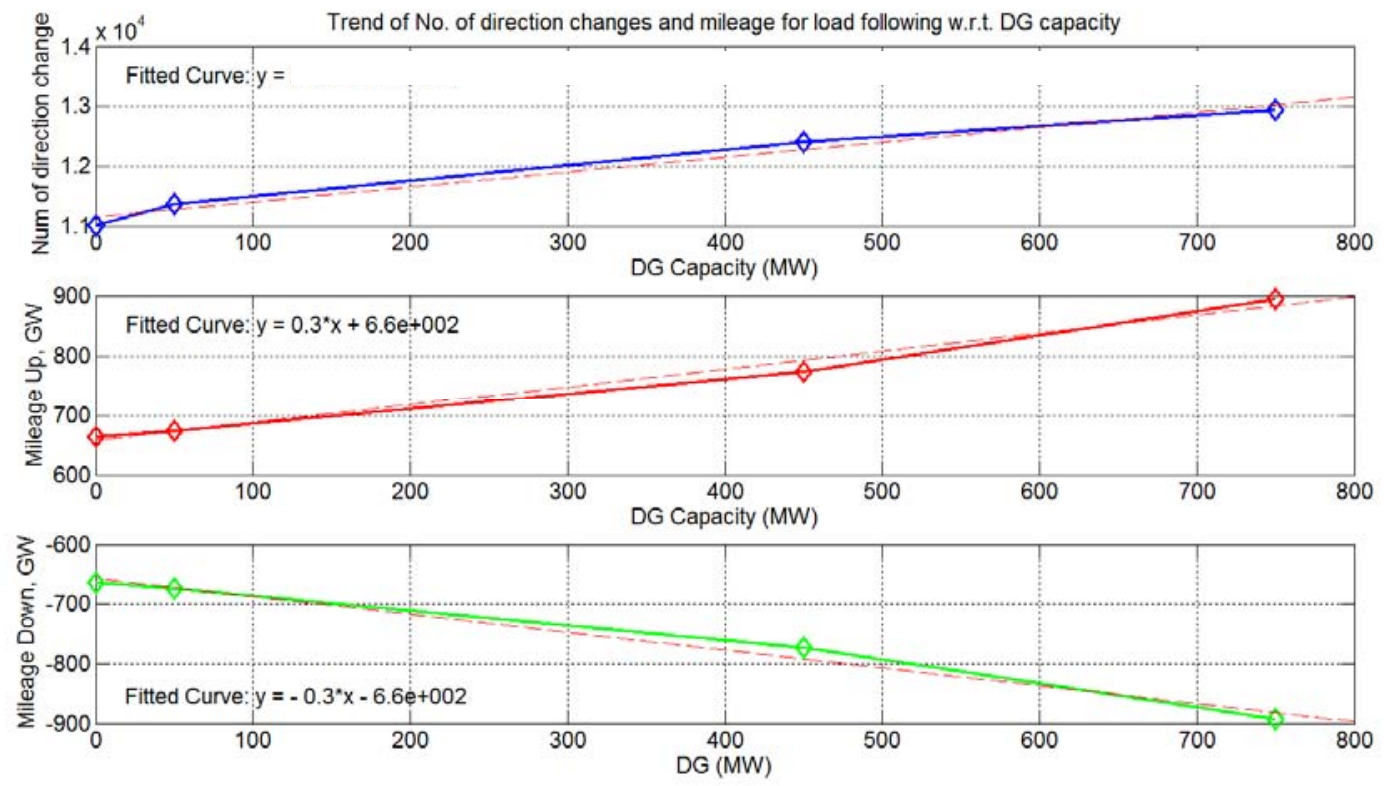

Figure 4-4. Comparison of yearly load following mileage and direction changes with regard to DG capacity (Study scenarios: Base Case, 1A, 1B, 1C)

Figure 4-5 and Figure 4-6 show the yearly accumulated regulation mileages and number of direction changes with respect to large PV and DG capacity, respectively. From Figure 4-5, an increase of 1 MW in PV installed capacity can cause 7.9 more direction changes and $170 \mathrm{MW}$ of mileage increase (both up and down) in regulation process throughout a year. An increase of 1 MW in DG installed capacity can cause 8.5 more direction changes and $200 \mathrm{MW}$ of mileage increase (both up and down) in regulation process (see Figure 4-6). Overall, both the accumulated mileage of regulation and total number of direction changes are increased as a result of the increasing PV or DG capacity. 

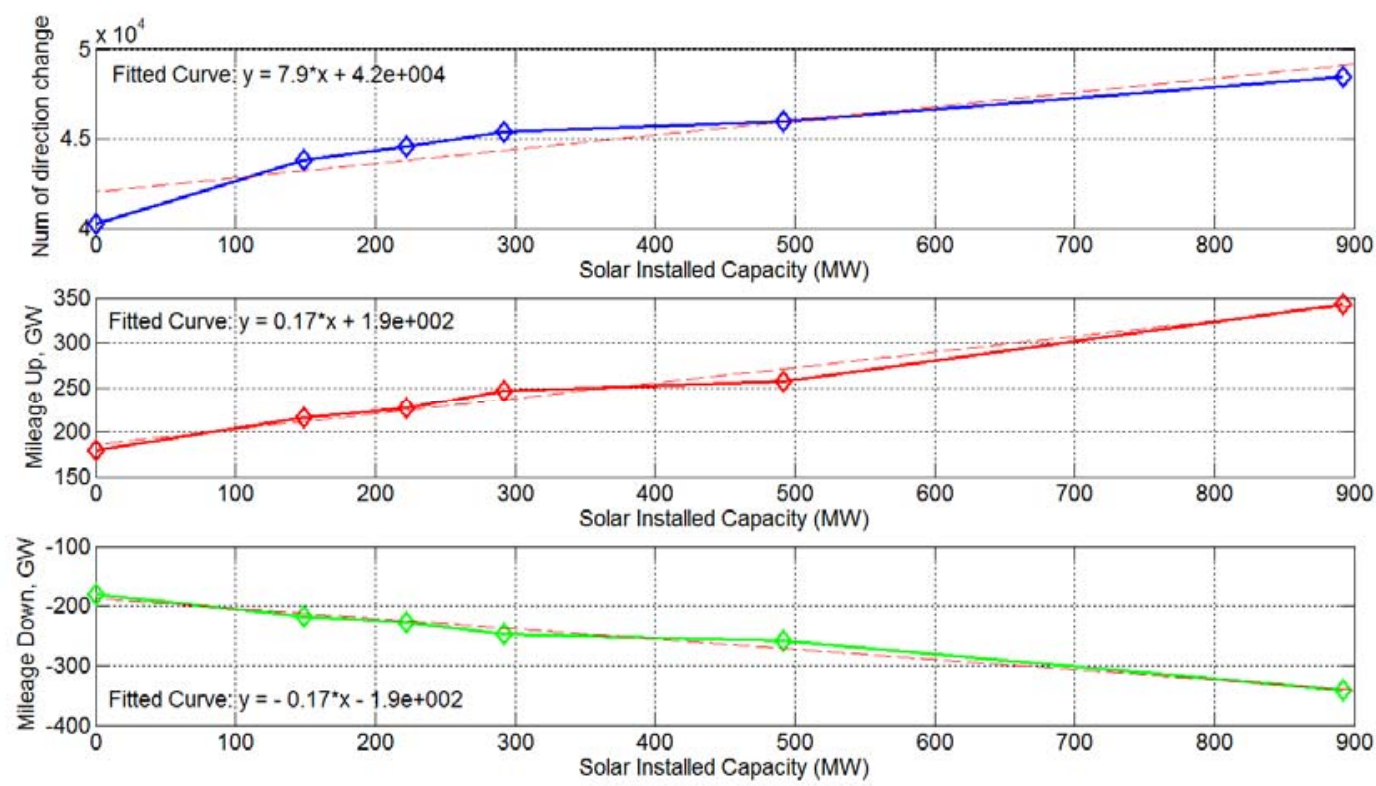

Figure 4-5. Comparison of yearly regulation mileage and direction changes with regard to large-scale PV capacity (Study scenarios: Base Case, 1A, 2A, 3A, 4A, 5A)
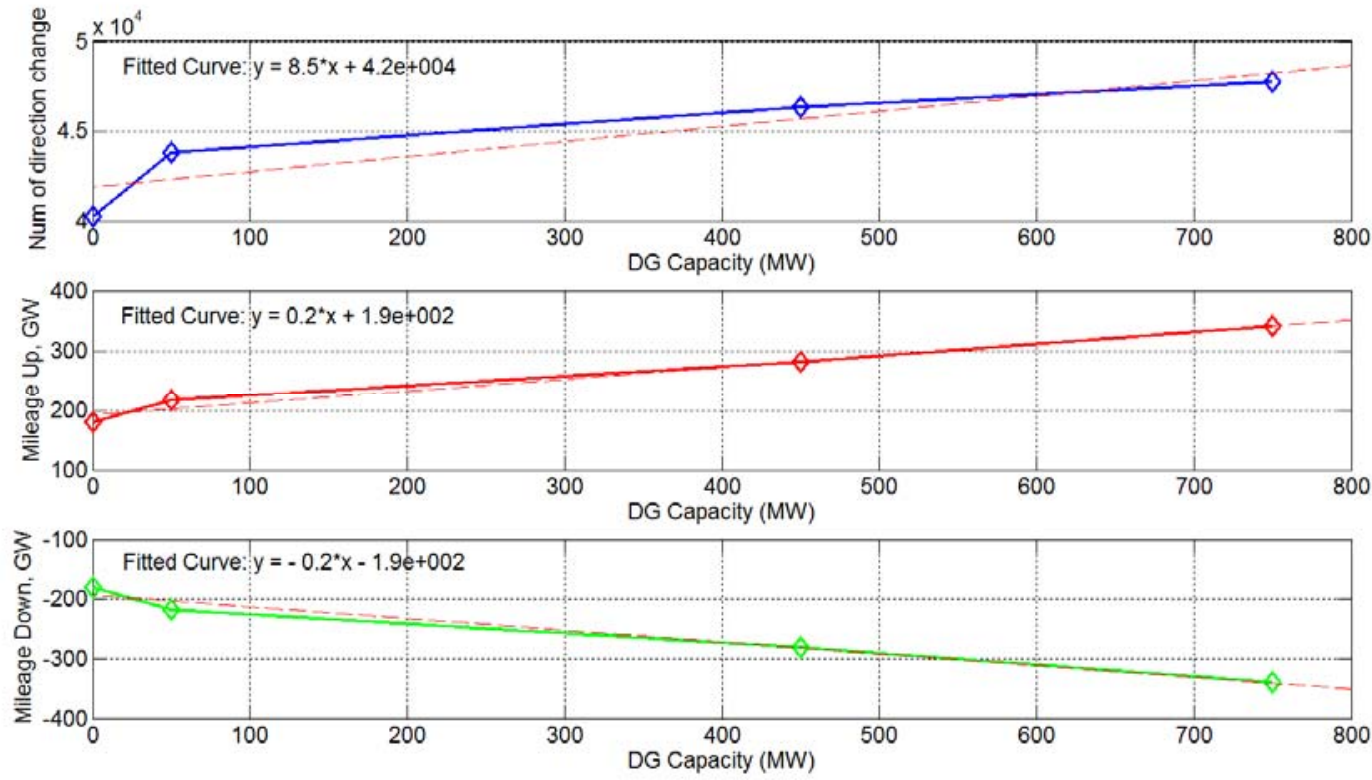

Figure 4-6. Comparison of yearly regulation mileage and direction changes with regard to DG capacity (Study scenarios: Base Case, 1A, 1B, 1C)

The trend plots are also generated for evaluating the solar impact on the generator movements during a single operating hour, 12 pm, as shown in Figure 4-7 through Figure 4-10. Similar trends of the number of direction changes and mileage in load following and regulation have been observed. For example, a 1 MW increase in PV capacity will cause 0.00043 times more direction changes and 0.027 MW/0.026 MW for moving up/down on a daily average for load following. 

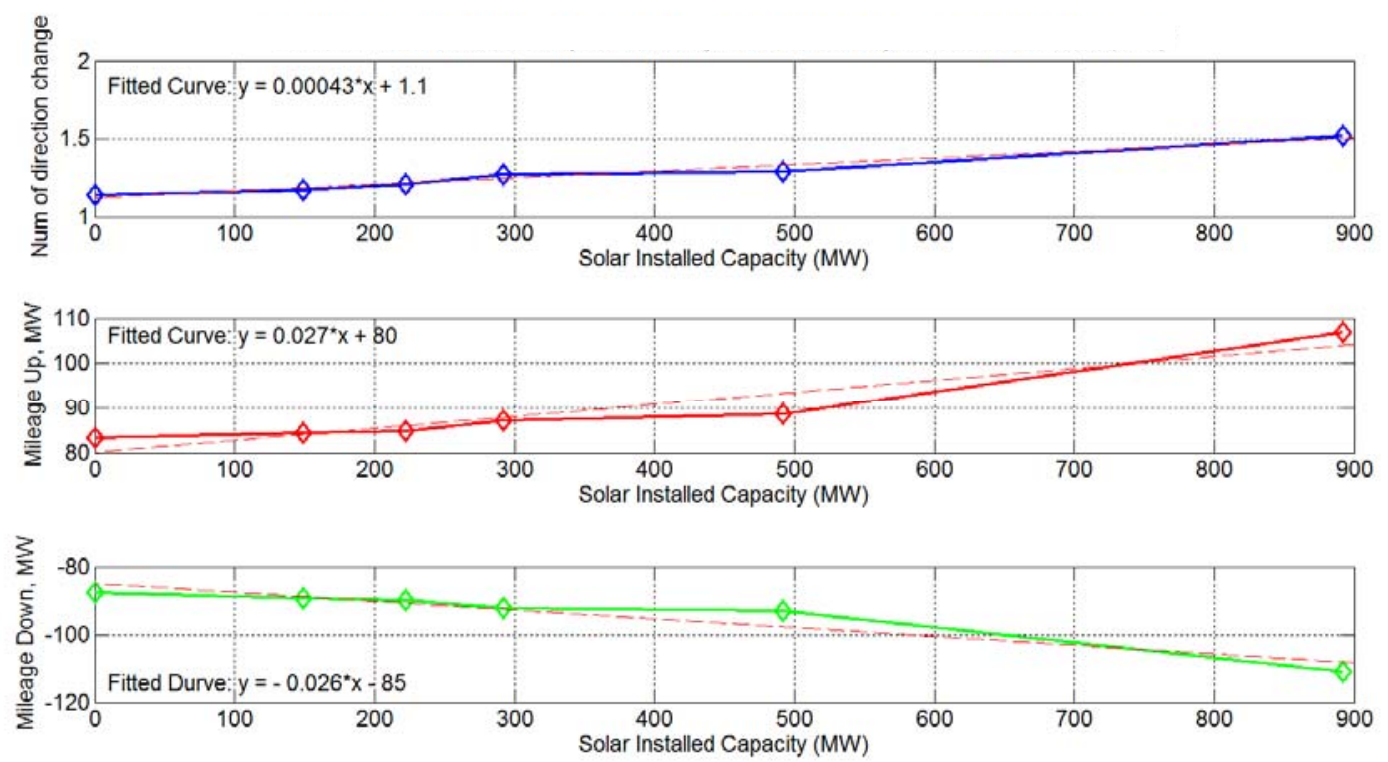

Figure 4-7. Comparison of average load following mileage and direction changes with regard to largescale PV capacity for operating hour 12 pm (study scenarios: Base Case, 1A, 2A, 3A, 4A, 5A)
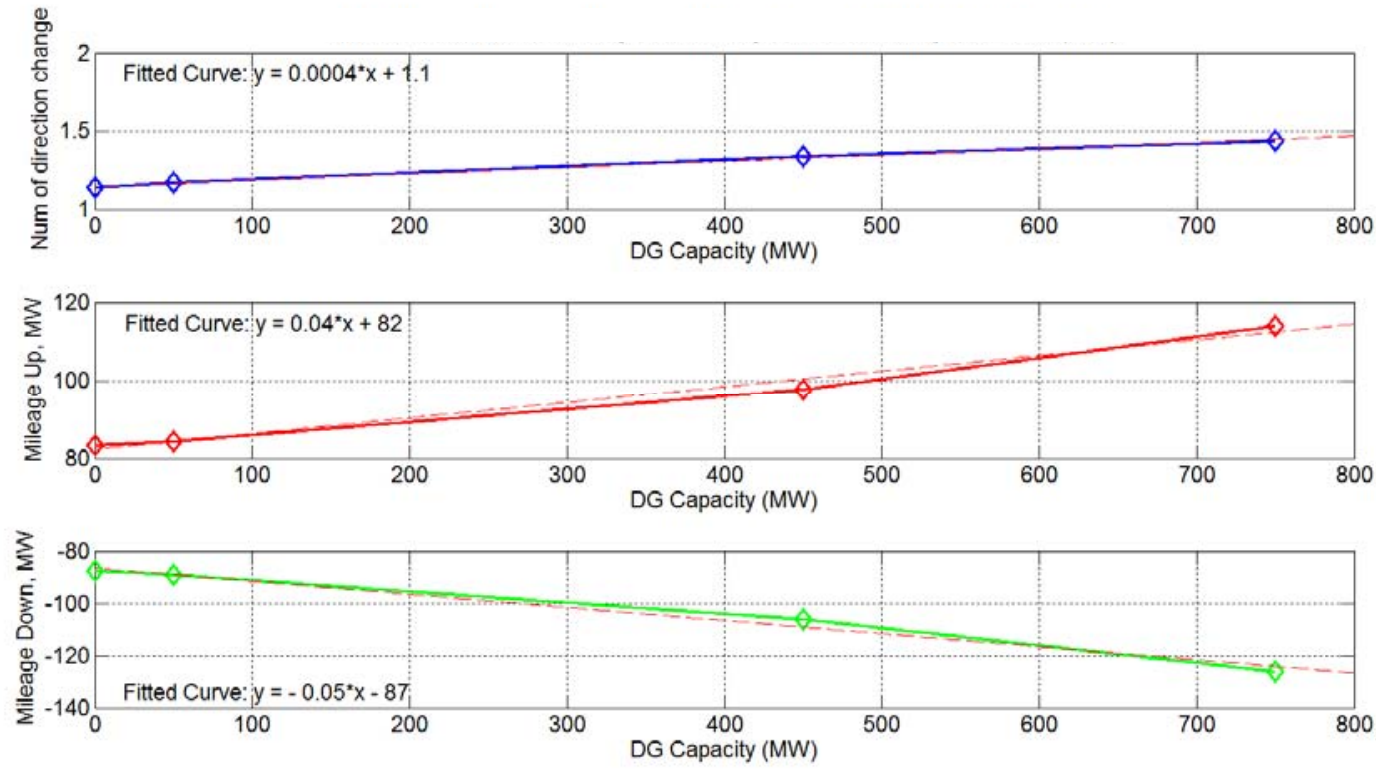

Figure 4-8. Comparison of average load following mileage and direction changes with regard to DG capacity for operating hour $12 \mathrm{pm}$ (study scenarios: Base Case, 1A, 1B, 1C) 

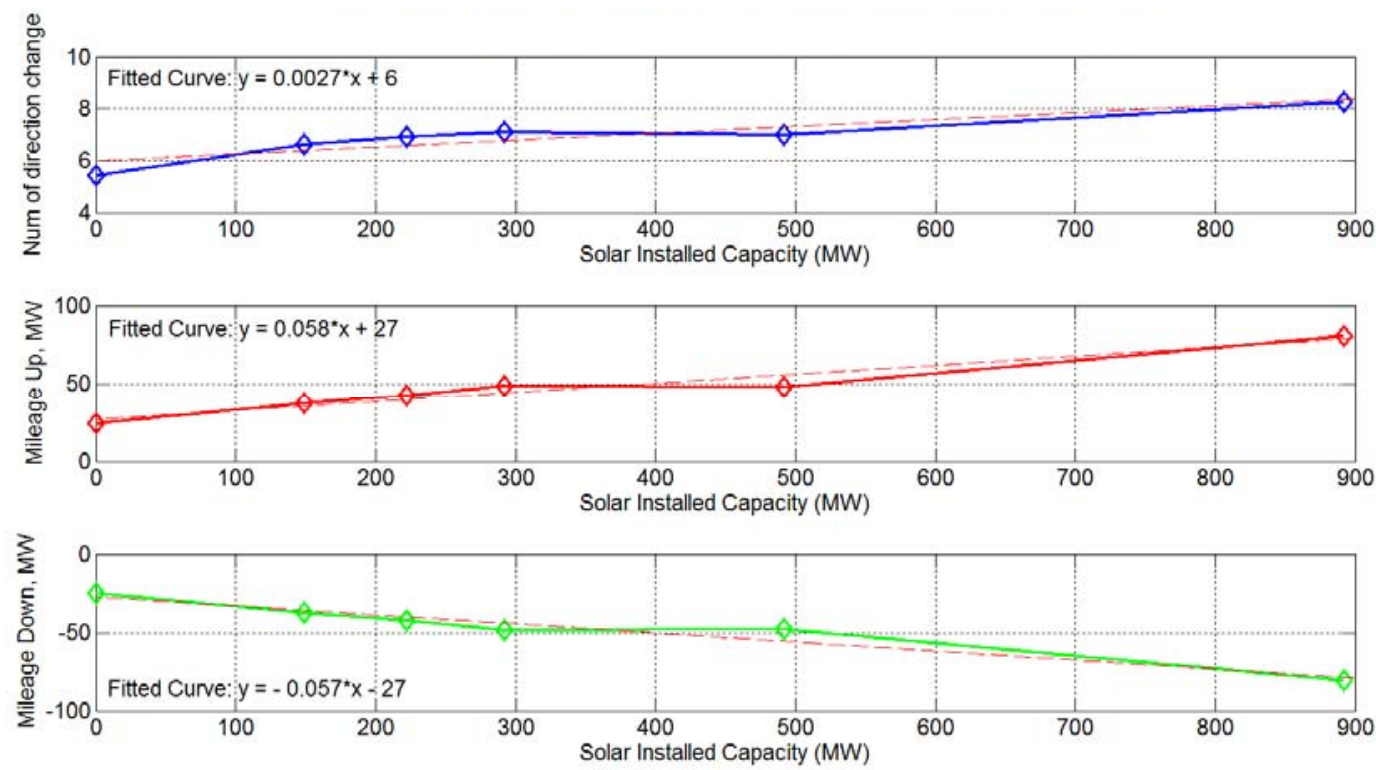

Figure 4-9. Comparison of average regulation mileage and direction changes with regard to large-scale PV capacity for operating hour 12 pm (study scenarios: Base Case, 1A, 2A, 3A, 4A, 5A)
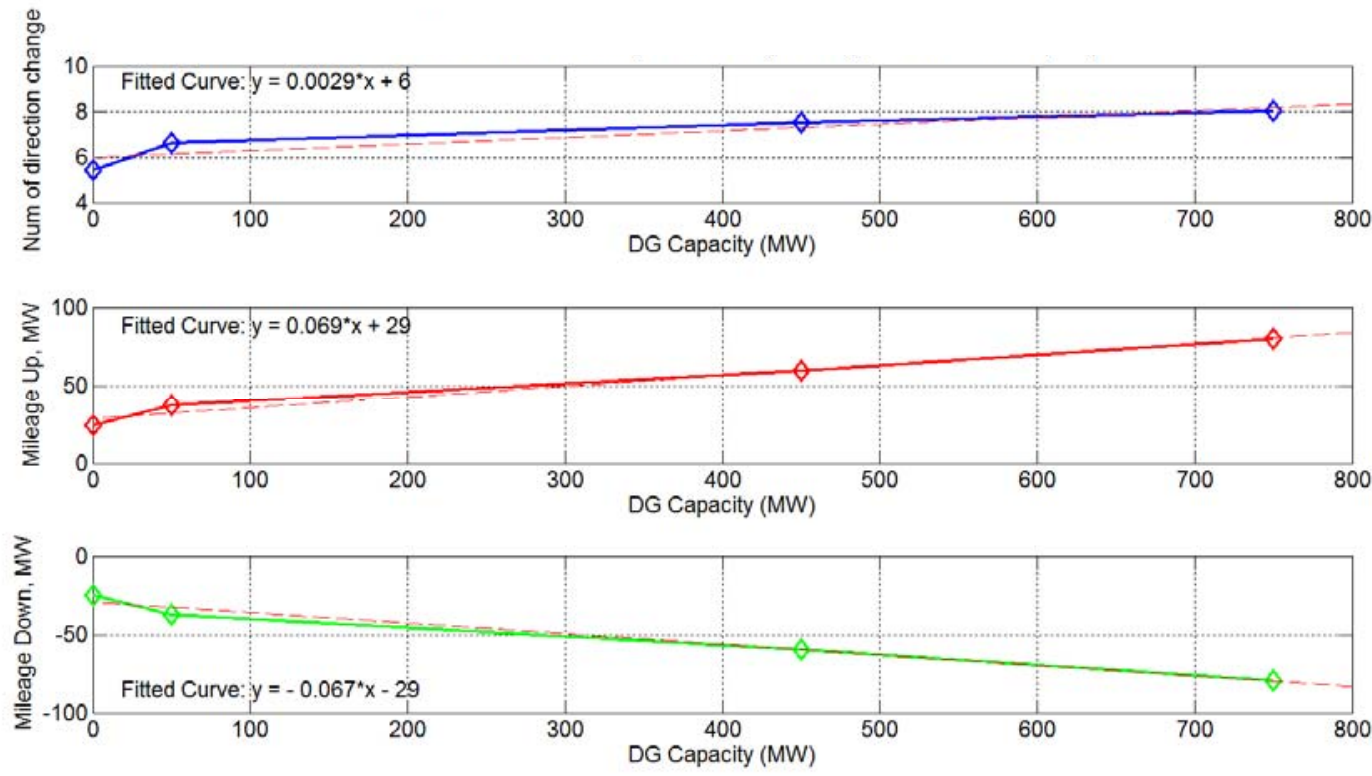

Figure 4-10. Comparison of average regulation mileage and direction changes with regard to DG capacity for operating hour 12 pm (study scenarios: Base Case, 1A, 1B, 1C)

To summarize, the proposed metrics can effectively demonstrate the impact of increased PV/DG capacity on the movements of conventional generators to provide load following and regulation services. In this study, regulation ramps with a magnitude lower than $20 \mathrm{MW}$ were ignored to reflect the AGC deadband in the Nevada system. All the simulation results in this section have pointed out that increase in solar installed capacity (both large PV and DG) will require more movements from generators to provide additional balancing services. Linear curve fitting method is used to approximate the generator 
movements (number of direction changes, mileage up and mileage down) with respect to PV and DG installed capacity. The derived linear relationships are further summarized in Table 4-1. By comparing the slope of DG curves with that of PV curves, it can be concluded that the DG installed capacity in Nevada system has a larger impact than large-scale PV in increasing the total balancing services. That means, to install the same amount of solar in Nevada system, DG requires more balancing services than large-scale PV.

Table 4-1. Summary of linear fitted curves

\begin{tabular}{|c|c|c|c|}
\hline \multicolumn{4}{|c|}{ Load following } \\
\hline$x \backslash y$ & Number of Direction Changes & $\begin{array}{l}\text { Mileage Up } \\
\text { (GW) }\end{array}$ & $\begin{array}{l}\text { Mileage Down } \\
\text { (GW) }\end{array}$ \\
\hline Large-scale PV (MW) & $y=2.3 x+1.1 * 10^{4}$ & $y=0.24 x+6.4 * 10^{2}$ & $y=-0.24 x-6.4 * 10^{2}$ \\
\hline DG (MW) & $y=2.5 x+1.1 * 10^{4}$ & $y=0.3 x+6.6 * 10^{2}$ & $y=-0.3 x-6.6 * 10^{2}$ \\
\hline \multicolumn{4}{|c|}{ Regulation } \\
\hline$x \backslash y$ & Number of Direction Changes & $\begin{array}{l}\text { Mileage Up } \\
\text { (GW) }\end{array}$ & $\begin{array}{l}\text { Mileage Down } \\
\text { (GW) }\end{array}$ \\
\hline Large-scale PV (MW) & $y=7.9 x+4.2 * 10^{4}$ & $y=0.17 x+1.9 * 10^{2}$ & $y=-0.17 x-1.9 * 10^{2}$ \\
\hline DG (MW) & $y=8.5 x+4.2 * 10^{4}$ & $y=0.2 x+1.9 * 10^{2}$ & $y=-0.2 x-1.9 * 10^{2}$ \\
\hline
\end{tabular}

\subsection{Ramp Statistics}

Table 4-2 and Table 4-3 compare the load following half-cycle occurring frequency of Base Case and Case 5A; while Table 4-4 and Table 4-5 compare the regulation half-cycle occurring frequency of the same scenarios. As can be observed in these tables, more solar generation can cause higher frequency of load following movements. More regulation movements with higher ramp rate and longer duration are also observed. The obtained ramp statistics for the other study cases are shown in Appendix B.

Table 4-2. Load Following Half-cycle Analysis for Base Case

\begin{tabular}{|c|c|c|c|c|c|c|c|c|c|c|c|c|c|}
\hline & & \multicolumn{12}{|c|}{ Load following half-cycle ramp rate in $\mathrm{MW} / \mathrm{min}$} \\
\hline \multirow{7}{*}{ 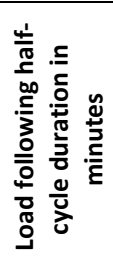 } & 0 & -55 & -45 & -35 & -25 & -15 & -5 & 5 & 15 & 25 & 35 & 45 & 55 \\
\hline & 10 & 0 & 0 & 0 & 0 & 14 & $\overline{112}$ & 110 & 8 & 0 & 0 & 0 & 0 \\
\hline & 30 & 1 & 1 & 3 & 31 & 374 & 2496 & 2882 & 356 & 6 & 1 & 1 & 1 \\
\hline & 50 & 0 & 0 & 0 & 0 & 0 & 1387 & 1159 & 0 & 0 & 0 & 0 & 0 \\
\hline & 70 & 0 & 0 & 0 & 0 & 0 & 230 & 233 & 1 & 0 & 0 & 0 & 0 \\
\hline & 90 & 0 & 0 & 0 & 0 & 0 & 249 & 197 & 0 & 0 & 0 & 0 & 0 \\
\hline & $>=110$ & 0 & 0 & 0 & 0 & 0 & 608 & 550 & 0 & 0 & 0 & 0 & 0 \\
\hline
\end{tabular}

Table 4-3. Load Following Half-cycle Analysis for Case 5A

\begin{tabular}{|c|c|c|c|c|c|c|c|c|c|c|c|c|c|}
\hline & & \multicolumn{12}{|c|}{ Load following half-cycle ramp rate in $\mathrm{MW} / \mathrm{min}$} \\
\hline \multirow{7}{*}{ 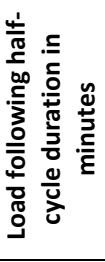 } & 0 & -55 & -45 & -35 & -25 & -15 & -5 & 5 & 15 & 25 & 35 & 45 & 55 \\
\hline & 10 & 0 & 0 & 0 & 0 & 78 & 504 & 384 & 56 & 0 & 0 & 0 & 0 \\
\hline & 30 & 1 & 1 & 6 & 37 & 543 & 2706 & 3584 & 445 & 7 & 2 & 1 & 1 \\
\hline & 50 & 0 & 0 & 0 & 0 & 9 & 1700 & 1235 & 18 & 0 & 0 & 0 & 0 \\
\hline & 70 & 0 & 0 & 0 & 0 & 0 & 257 & 236 & 1 & 0 & 0 & 0 & 0 \\
\hline & 90 & 0 & 0 & 0 & 0 & 0 & 238 & 188 & 1 & 0 & 0 & 0 & 0 \\
\hline & $>=110$ & 0 & 0 & 0 & 0 & 0 & 456 & 376 & 0 & 0 & 0 & 0 & 0 \\
\hline
\end{tabular}


Table 4-4. Regulation Half-cycle Analysis for Base Case

\begin{tabular}{|c|c|c|c|c|c|c|c|c|c|c|c|c|c|c|c|c|c|c|c|}
\hline \multirow{2}{*}{\multicolumn{2}{|c|}{$=$}} & \multicolumn{18}{|c|}{ Regulation half-cycle ramp rate in $\mathrm{MW} / \mathrm{min}$} \\
\hline \multirow{11}{*}{ 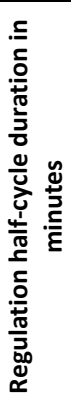 } & & -45 & -40 & -35 & -30 & -25 & -20 & -15 & -10 & -5 & 5 & 10 & 15 & 20 & 25 & 30 & 35 & 40 & 45 \\
\hline & 1 & 0 & 0 & 0 & 0 & 0 & 0 & 0 & 0 & 0 & 0 & 0 & 0 & 0 & 0 & 0 & 0 & 0 & 0 \\
\hline & 2 & 0 & 0 & 0 & 0 & 1 & 2 & 8 & 352 & 2261 & 2217 & 370 & 4 & 3 & 0 & 1 & 1 & 2 & 0 \\
\hline & 3 & 0 & 0 & 0 & 0 & 0 & 1 & 1 & 19 & 1331 & 1348 & 15 & 1 & 1 & 0 & 0 & 0 & 0 & 1 \\
\hline & $\overline{4}$ & 0 & 0 & 0 & 0 & 0 & 0 & 0 & 4 & 815 & 743 & 5 & 2 & 1 & 1 & 0 & 0 & 0 & 0 \\
\hline & 5 & 0 & 0 & 0 & 0 & 0 & 0 & 0 & 2 & 400 & 409 & 2 & 0 & 1 & 0 & 0 & 0 & 0 & 0 \\
\hline & 6 & 0 & 0 & 0 & 0 & 0 & 0 & 0 & 0 & 223 & 188 & 1 & 0 & 0 & 0 & 0 & 0 & 0 & 0 \\
\hline & 7 & 0 & 0 & 0 & 0 & 0 & 1 & 0 & 0 & 74 & 86 & 1 & 1 & 0 & 0 & 0 & 0 & 0 & 0 \\
\hline & 8 & 0 & 0 & 0 & 0 & 0 & 0 & 0 & 2 & 39 & 41 & 0 & 0 & 0 & 0 & 0 & 0 & 0 & 0 \\
\hline & 9 & 0 & 0 & 0 & 0 & 0 & 0 & 0 & 0 & 20 & 31 & 1 & 0 & 0 & 0 & 0 & 0 & 0 & 0 \\
\hline & $>=10$ & 0 & 0 & 0 & 0 & 0 & 0 & 0 & 0 & 27 & 27 & 0 & 0 & 0 & 0 & 0 & 0 & 0 & 0 \\
\hline
\end{tabular}

Table 4-5. Regulation Half-cycle Analysis for Case 5A

\begin{tabular}{|c|c|c|c|c|c|c|c|c|c|c|c|c|c|c|c|c|c|c|c|}
\hline & & \multicolumn{18}{|c|}{ Regulation half-cycle ramp rate in $\mathrm{MW} / \mathrm{min}$} \\
\hline \multirow{11}{*}{ 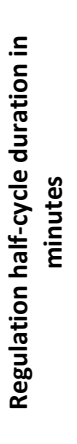 } & 0 & -45 & -40 & -35 & -30 & -25 & -20 & -15 & -10 & -5 & 5 & 10 & 15 & 20 & 25 & 30 & 35 & 40 & 45 \\
\hline & 1 & 0 & 0 & 0 & 0 & 0 & 0 & 0 & 0 & 0 & 0 & 0 & 0 & 0 & 0 & 0 & 0 & 0 & 0 \\
\hline & 2 & 0 & 2 & 1 & 1 & 6 & 8 & 38 & 579 & 2466 & 2422 & 608 & 31 & 9 & 2 & 1 & 4 & 2 & 1 \\
\hline & 3 & 0 & 2 & 1 & 0 & 6 & 16 & 46 & 212 & 1693 & 1747 & 207 & 51 & 13 & 5 & 2 & 3 & 3 & 3 \\
\hline & 4 & 1 & 1 & 1 & 4 & 7 & 16 & 37 & 148 & 1186 & 1137 & 170 & 27 & 22 & 8 & 1 & 2 & 1 & 1 \\
\hline & 5 & 0 & 0 & 0 & 4 & 4 & 19 & 26 & 108 & 867 & 855 & 107 & 32 & 22 & 8 & 5 & 0 & 0 & 0 \\
\hline & 6 & 0 & 0 & 0 & 4 & 5 & 10 & 31 & 79 & 566 & 556 & 78 & 22 & 11 & 7 & 2 & 1 & 0 & 0 \\
\hline & 7 & 0 & 0 & 0 & 0 & 2 & 6 & 16 & 54 & 385 & 345 & 60 & 20 & 7 & 2 & 0 & 0 & 0 & 0 \\
\hline & 8 & 0 & 0 & 0 & 1 & 1 & 3 & 12 & 37 & 272 & 279 & 48 & 10 & 4 & 1 & 1 & 0 & 0 & 0 \\
\hline & 9 & 0 & 0 & 0 & 0 & 0 & 3 & 8 & 25 & 189 & 201 & 31 & 5 & 3 & 0 & 0 & 0 & 0 & 0 \\
\hline & $>=10$ & 0 & 0 & 0 & 0 & 1 & 1 & 8 & 35 & 470 & 447 & 29 & 4 & 0 & 0 & 0 & 0 & 0 & 0 \\
\hline
\end{tabular}

Figure 4-11 through Figure 4-14 create trend plots of average half-cycle magnitude for load following/regulation with respect to large-scale PV and DG capacity, respectively. A 1MW increase in large-scale PV capacity can cause the average half-cycle magnitude of load following to increase 0.015 MW for both up and down directions; the same amount of increase in DG capacity can increase 0.023 MW in the average half-cycle magnitude of load following. Table 4-6 summarizes and compares the derived linear curves from Figure 4-11 to Figure 4-14. It is found that all of the average half-cycle magnitude curves (both positive and negative) are increased as a result of increased solar capacity, for both large-scale PV and DG. The impact of PV is larger than DG in causing more load following and regulation movements.

Table 4-6. Summary of linear fitted curves

\begin{tabular}{|c|c|c|}
\hline \multicolumn{3}{|c|}{ Load following } \\
\hline $\mathbf{x} \backslash \mathbf{y}$ & Avg. Half-cycle Mag., Up (MW) & Avg. Half-cycle Mag., Down (MW) \\
\hline $\begin{array}{c}\text { Large-scale PV } \\
\text { (MW) }\end{array}$ & $\mathrm{y}=0.015 \mathrm{x}+1.2 * 10^{2}$ & $\mathrm{y}=-0.015 \mathrm{x}-1.2 * 10^{2}$ \\
\hline DG (MW) & $\mathrm{y}=0.023 \mathrm{x}+1.2 * 10^{2}$ & $\mathrm{y}=-0.023 \mathrm{x}-1.2 * 10^{2}$ \\
\hline \multicolumn{2}{|c|}{ Regulation } \\
\hline $\mathbf{3}$ (M) & Mileage Up (GW) & Mileage Down (GW) \\
\hline $\begin{array}{c}\text { Large-scale PV } \\
\text { (MW) }\end{array}$ & $\mathrm{y}=0.0057 \mathrm{x}+9$ & $\mathrm{y}=-0.0056 \mathrm{x}-9$ \\
\hline DG (MW) & $\mathrm{y}=0.0067 \mathrm{x}+9.2$ & $\mathrm{y}=-0.0066 \mathrm{x}-9.2$ \\
\hline
\end{tabular}






Figure 4-11. Comparison of average load following half-cycle magnitude with regard to large-scale PV capacity (Study scenarios: Base Case, 1A, 2A, 3A, 4A, 5A)

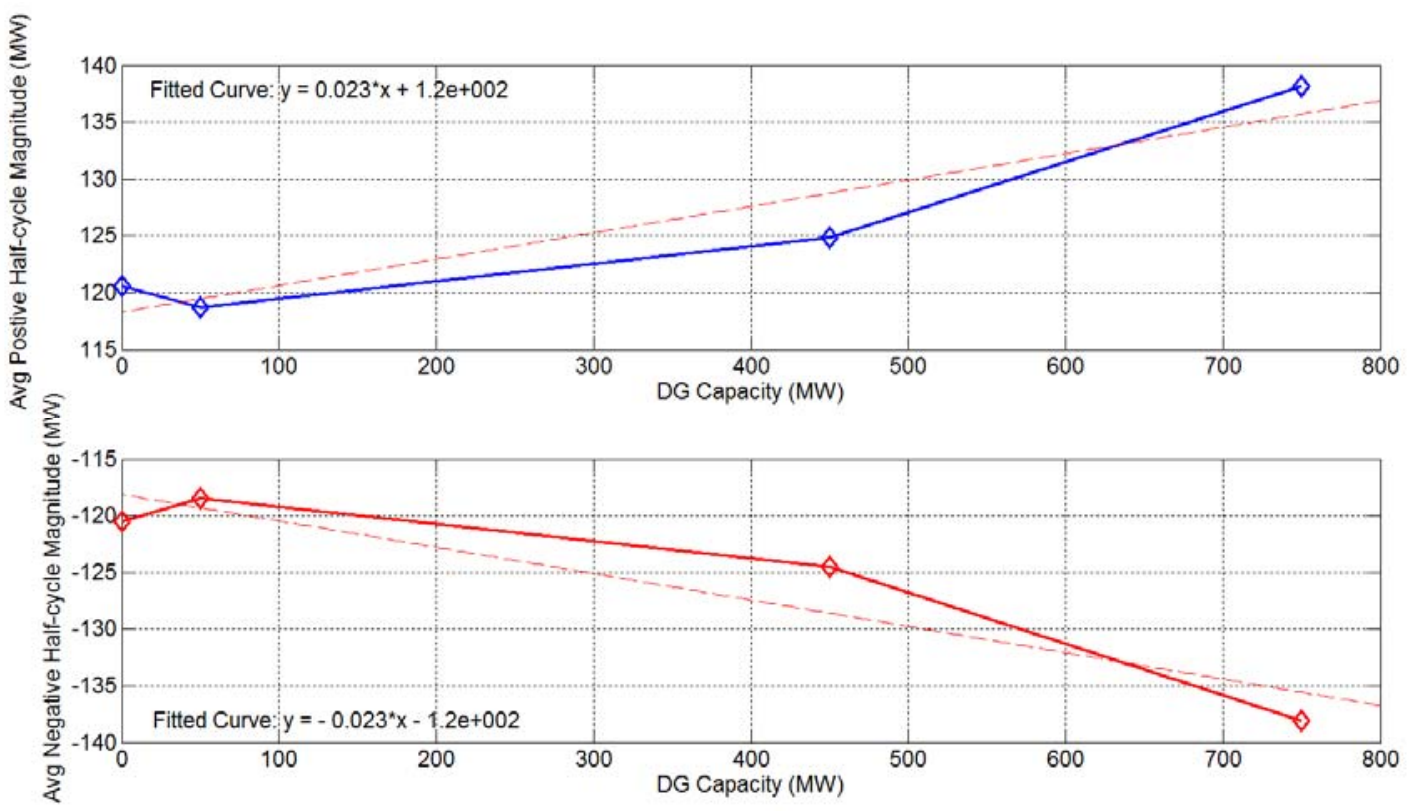

Figure 4-12. Comparison of average load following half-cycle magnitude with regard to DG capacity (Study scenarios: Base Case, 1A, 1B, 1C) 


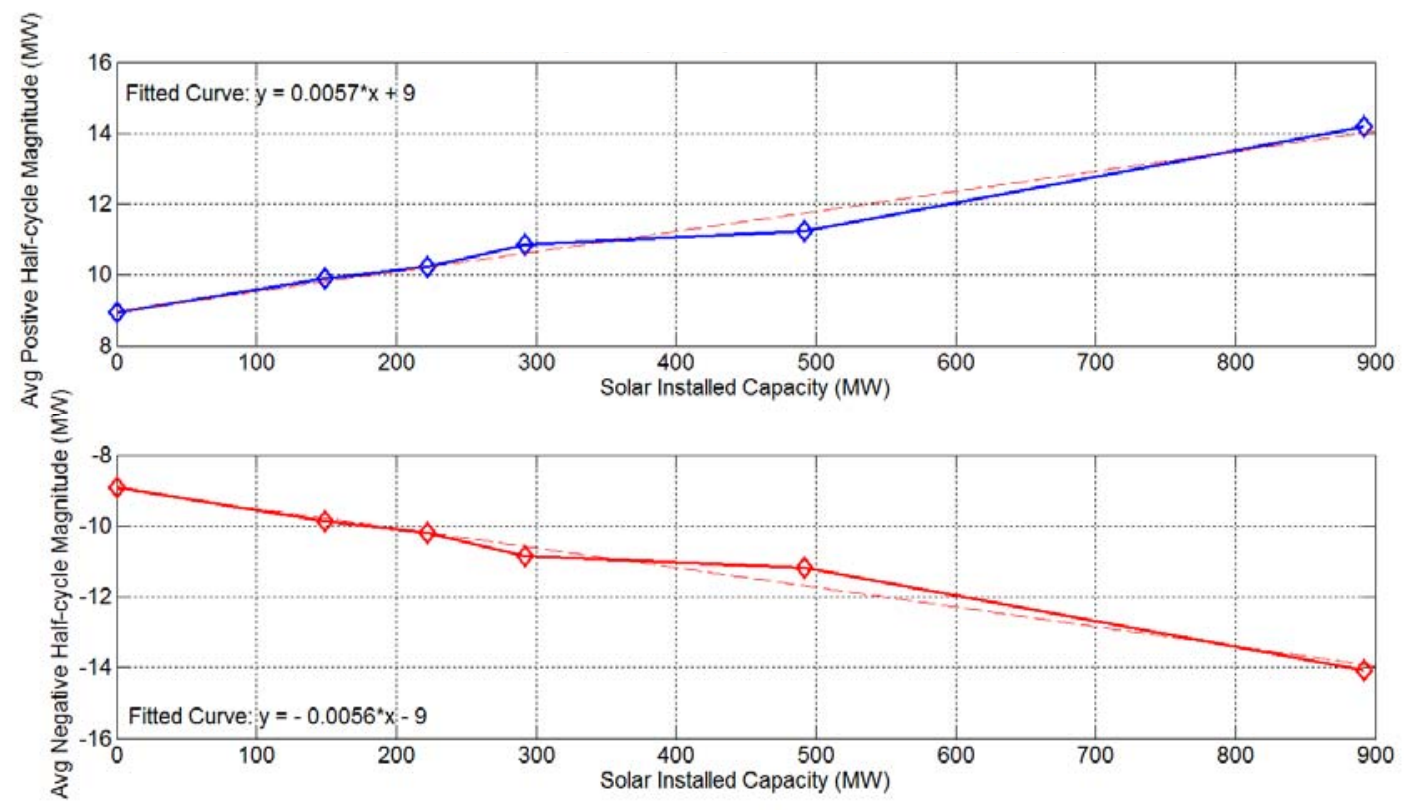

Figure 4-13. Comparison of average regulation half-cycle magnitude with regard to large-scale PV capacity (Study scenarios: Base Case, 1A, 2A, 3A, 4A, 5A)

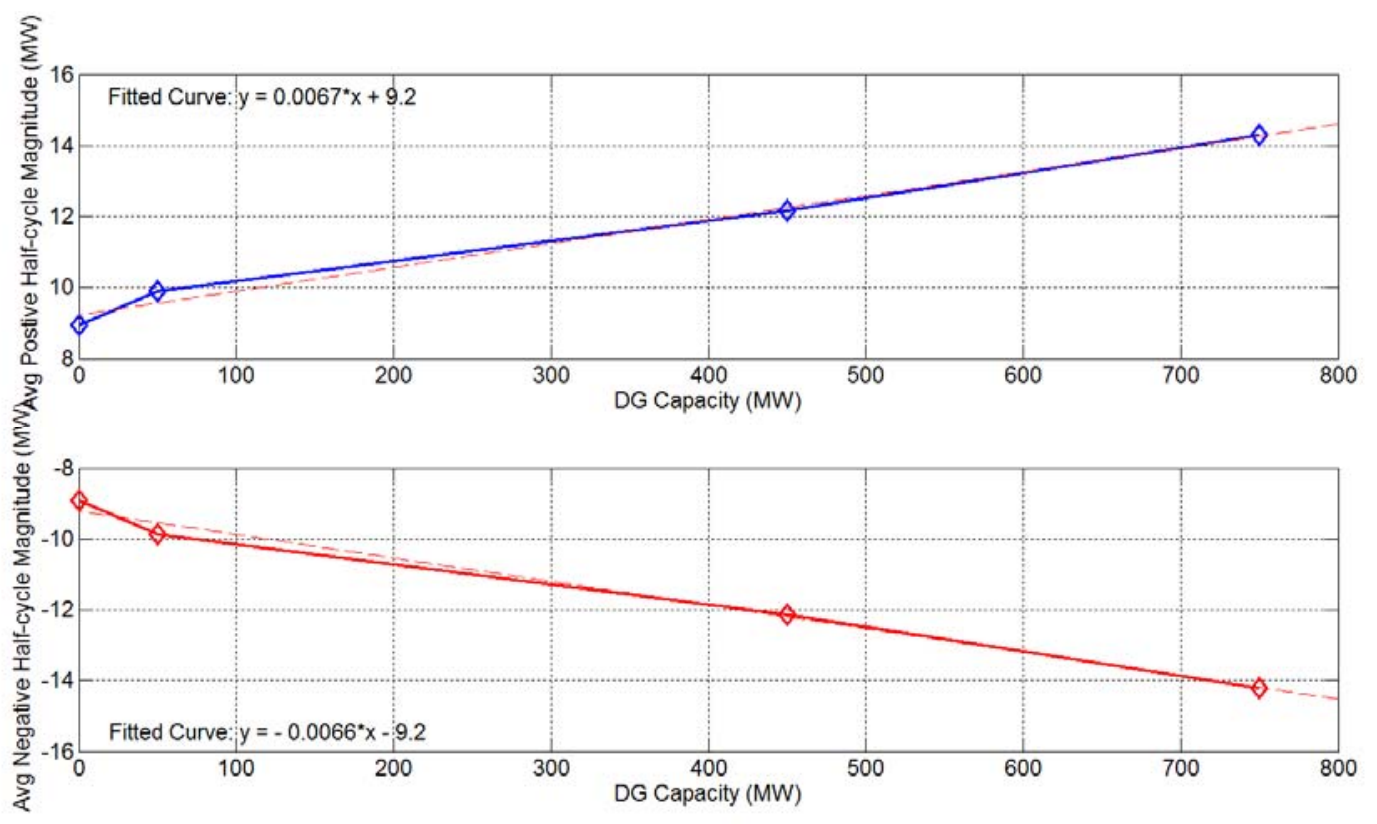

Figure 4-14. Comparison of average regulation half-cycle magnitude with regard to DG capacity (Study scenarios: Base Case, 1A, 1B, 1C) 


\subsection{Conclusions}

This report develops two major metrics to evaluate the cycling and movements of conventional generators in the southern Nevada power system. The proposed metrics can effectively quantify the wear and tear on the conventional units for balancing the system. Metric 1 calculates the total mileage traveled in MW and number of direction changes to provide balancing services; and Metric 2 performs ramp/half-cycle analysis by generating three-dimensional histograms for load following or regulation ramps to evaluate the impact of large-scale PV and DG on the system. From the above analysis results, the following conclusions can be drawn:

(1) For load following, three busy periods are identified:

a. 9:00 am 11:00 am (the morning peak), valid for cases (Base, 1A, 2A, 3A)

b. $15: 00 \mathrm{pm} \sim 17: 00 \mathrm{pm}$ (the afternoon peak), valid for cases (1A, 1B, 1C, 2A, 3A, 3C, 4A, $4 \mathrm{~B}, 5 \mathrm{~A})$

c. 22:00 $\mathrm{pm} \sim 1$ :00 am (the midnight peak), valid for cases (Base, 1A, 1B, 1C, 2A, 3A, 3C, 4A, 4B)

(2) For regulation, no particular busy hours are observed for cases with little solar penetration (e.g., Base Case). For those cases with more solar power, the regulation busy hours focus on the period from 10:00 am to 16:00 pm (e.g. ,Cases 1C, 3A, 3C), when the solar irradiation is supposed to reach the maximum level.

(3) From Metric 2 results, it can be observed that higher penetration of large PV and DG can cause more high-ramp rate events with longer ramp duration, which poses larger ramp and capacity reserve requirements on conventional generators.

(4) Overall, a higher solar penetration will result in more direction changes on load following and regulation. Also, higher solar penetrations will lead to larger mileages, i.e., MW traveled by conventional generators to meet load following and regulation requirements.

This analysis provides a basis for the evaluation of generator cycling and movements for the integration of solar power. The metrics developed can be used to analyze generator wear and tear and associated maintenance cost if the cost data are available. 


\subsection{References}

[1]. Y. V. Makarov, P. V. Etingov, N. Zhou, J. Ma, N.A. Samaan, R. Diao, S.V. Malhara, R.T. Guttromson, P. Du, and C. Sastry, 2010. “Analysis Methodology for Balancing Authority Cooperation in High Penetration of Variable Generation” PNNL-19229, Pacific Northwest National Laboratory, Richland, WA. [Online]

Available: http://www.pnl.gov/main/publications/external/technical_reports/PNNL-19229.pdf

[2]. Y.V. Makarov, S. Lu, B. McManus, J. Pease, 2008. “The Future Impact of Wind on BPA Power System Ancillary Services”, IEEE Transmission and Distribution Conference 2008, Chicago, April 2008.

[3]. Y. V. Makarov, C. Loutan, J. Ma and P. de Mello, 2009. “Operational Impacts of Wind Generation on California Power Systems”, IEEE Transactions on Power Systems, vol. 24, no. 2, pp. 1039-1050, May 2009. 


\section{APPENDIX A}

Daily Average Mileage and Number of Direction Changes of Load Following and Regulation for Cases:

1A, 2A, 3A, 4A, 1B, 4B, 1C and 3C 


\section{Appendix A}

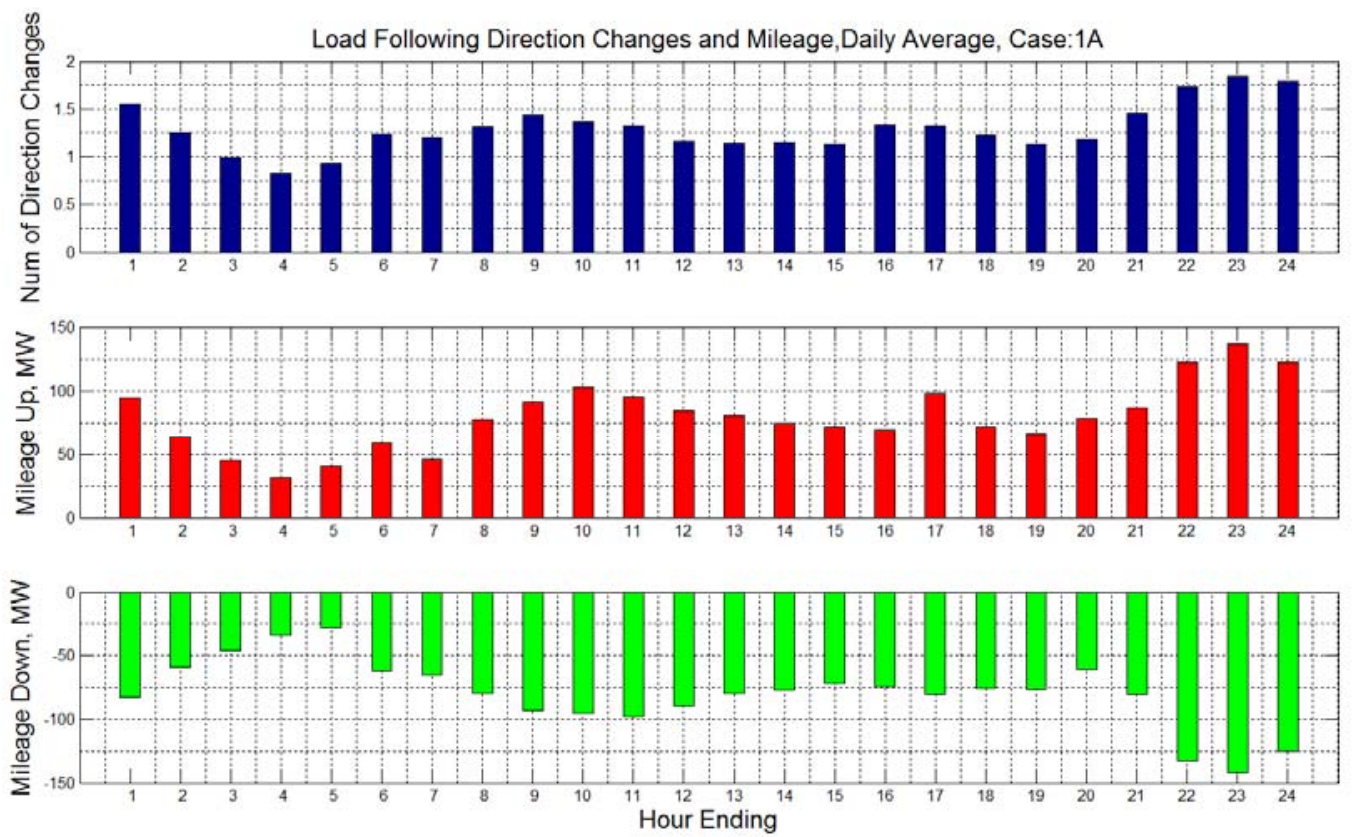

Figure A-1. Daily average of direction changes and mileage for load following in Case 1A
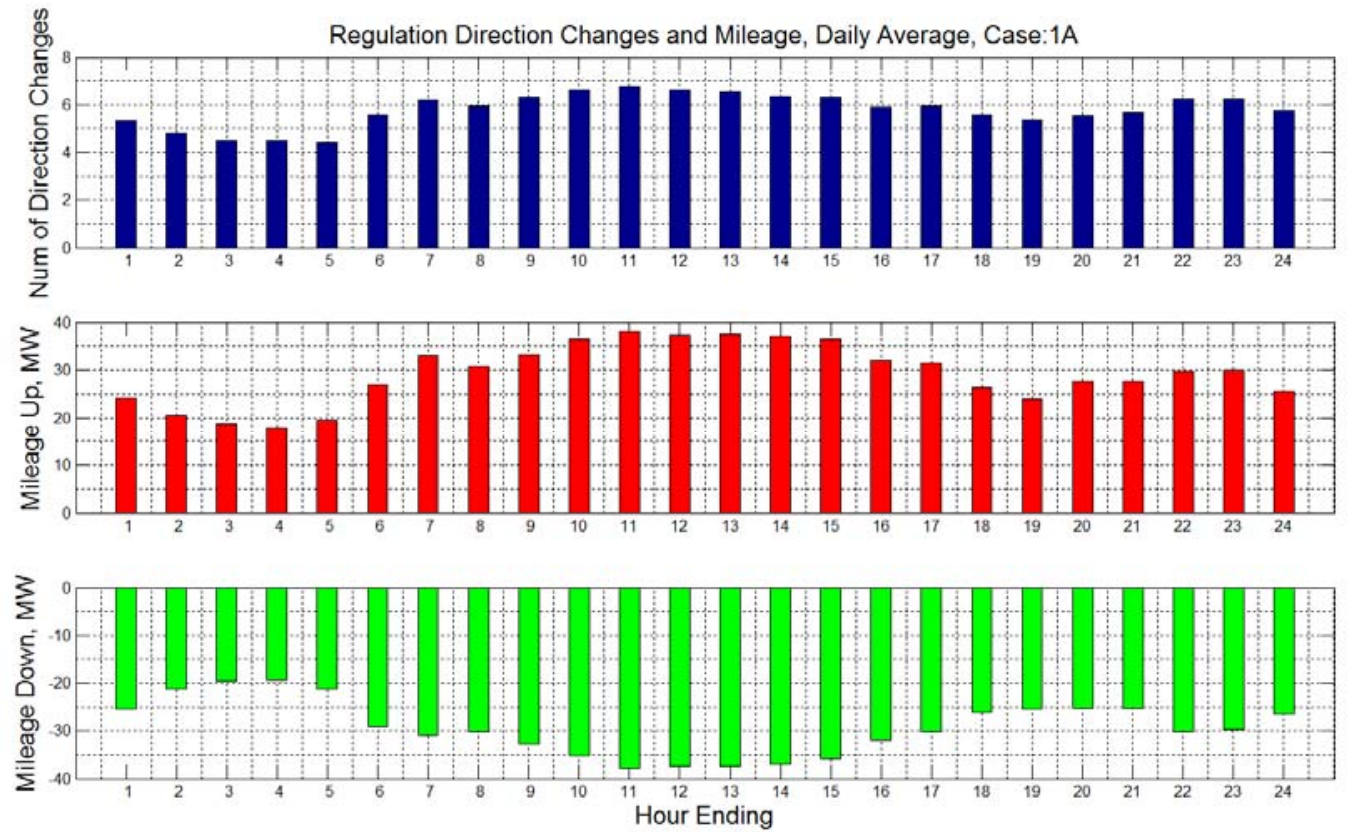

Figure A-2. Daily average of direction changes and mileage for regulation in Case 1A 

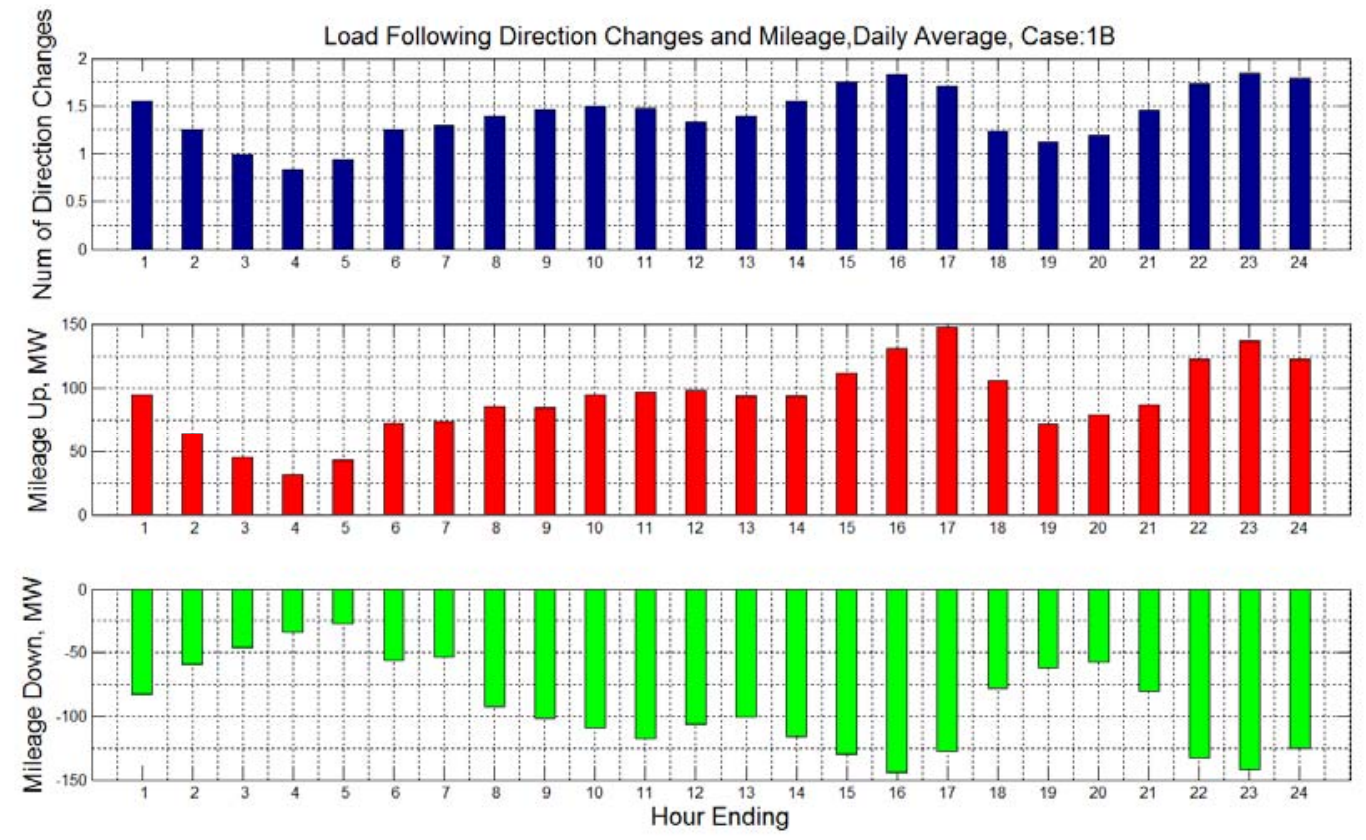

Figure A-3. Daily average of direction changes and mileage for load following in Case 1B


Figure A-4. Daily average of direction changes and mileage for regulation in Case 1B 

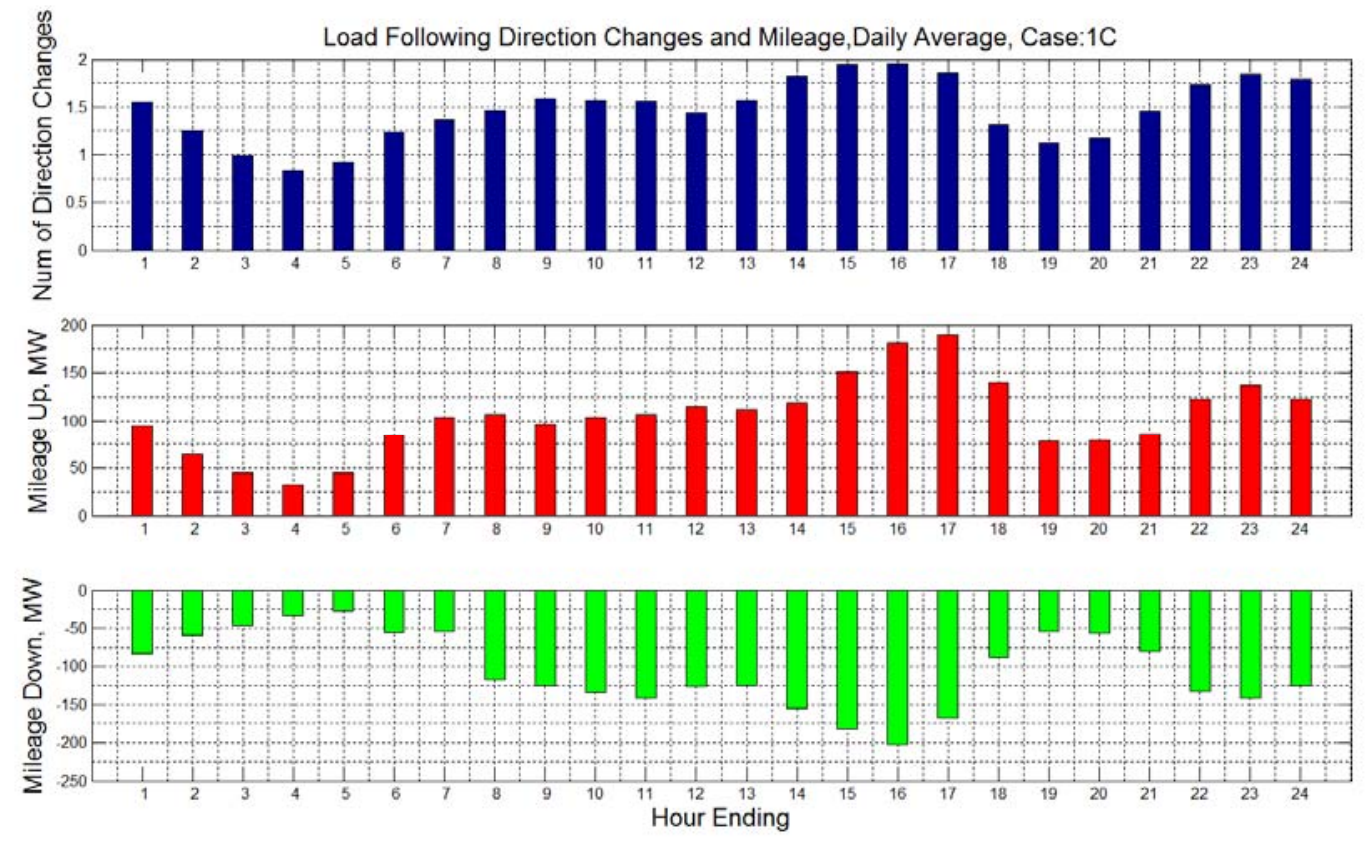

Figure A-5. Daily average of direction changes and mileage for load following in Case 1C


Figure A-6. Daily average of direction changes and mileage for regulation in Case 1C 

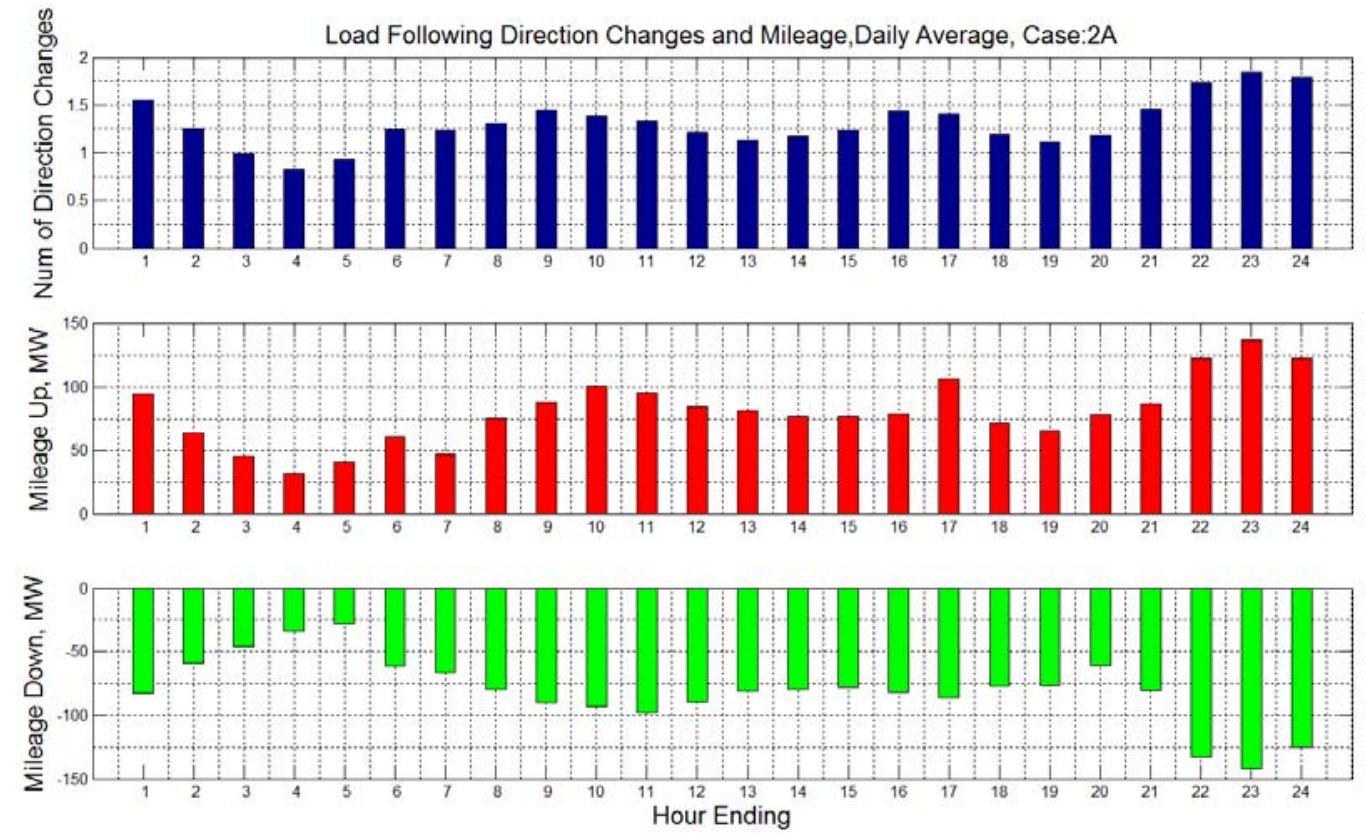

Figure A-7. Daily average of direction changes and mileage for load following in Case 2A
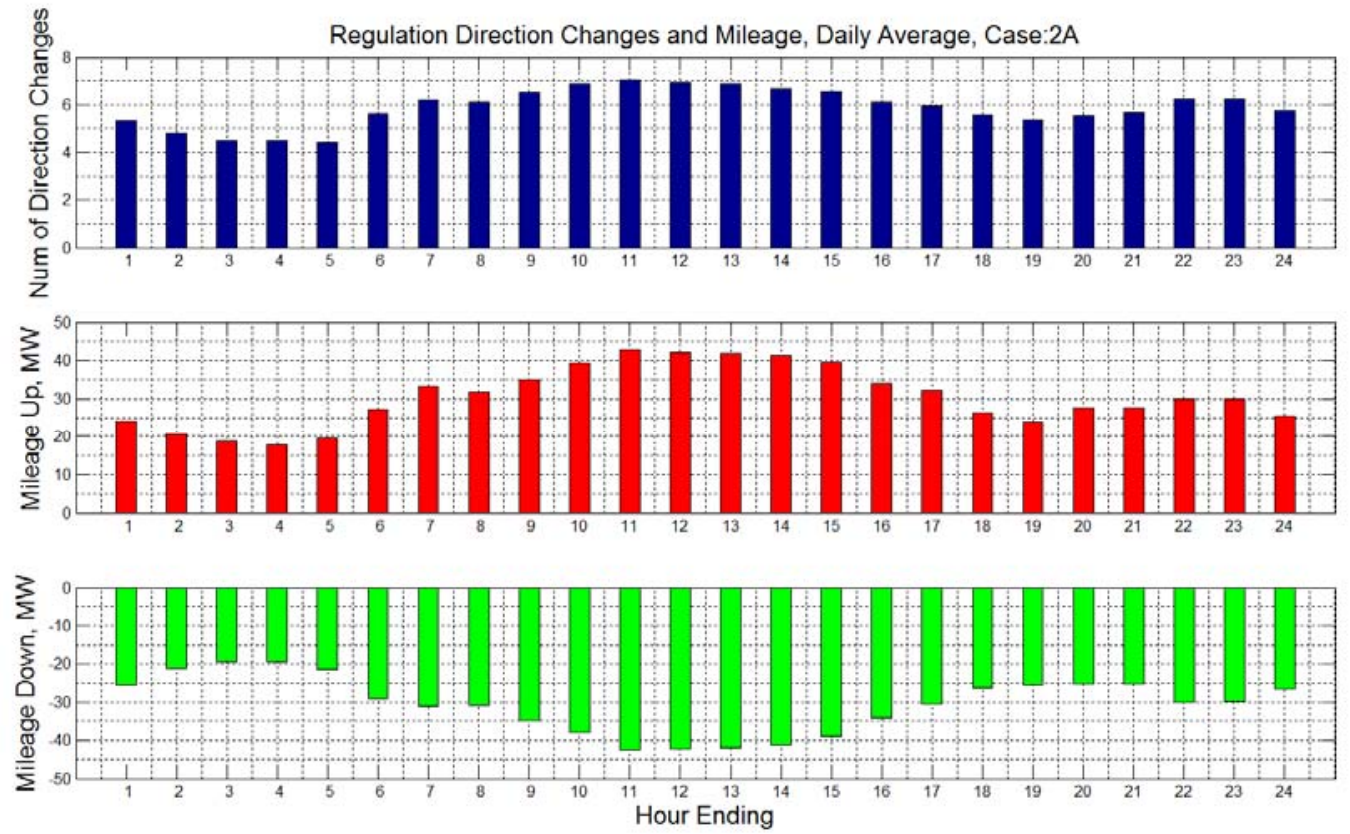

Figure A-8. Daily average of direction changes and mileage for regulation in Case 2A 



Figure A-9. Daily average of direction changes and mileage for load following in Case 3A
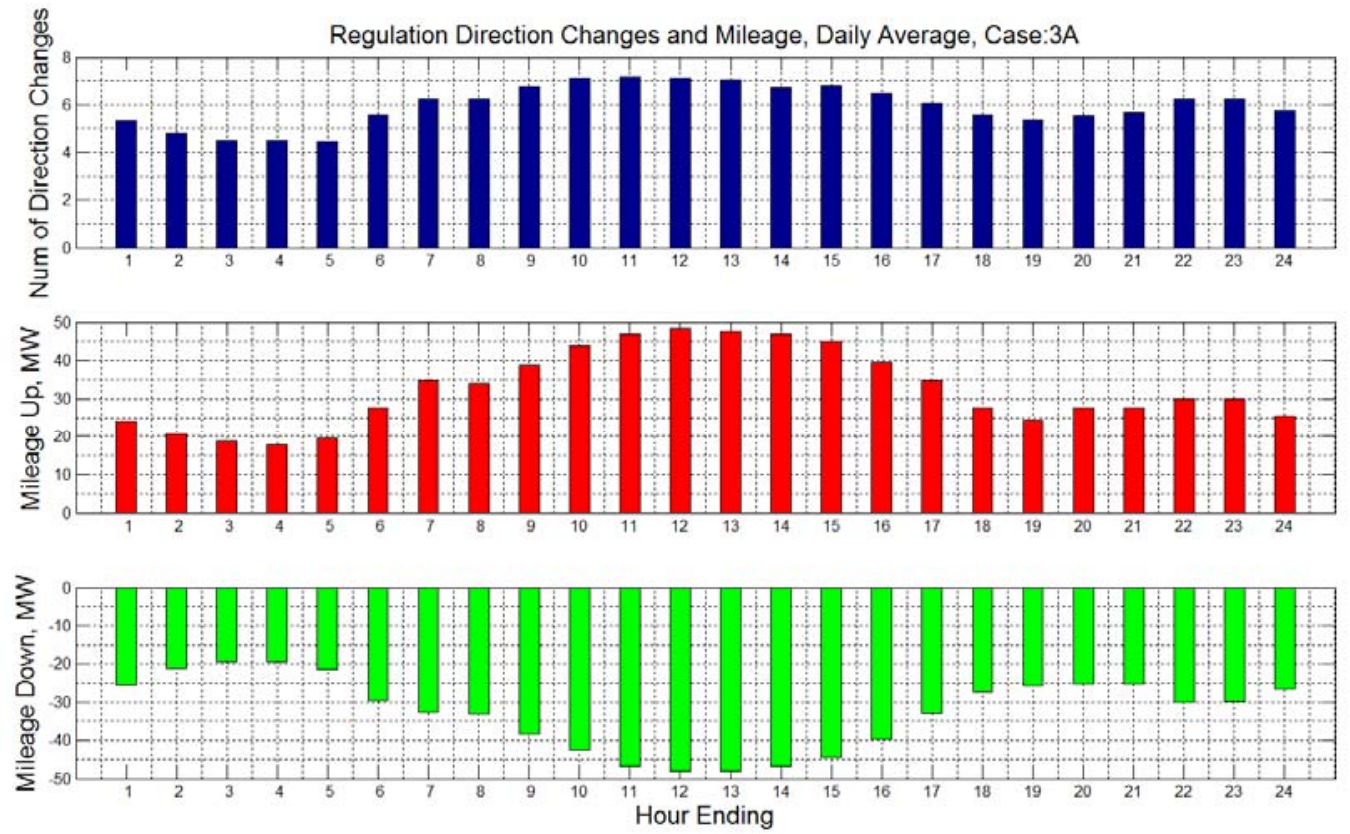

Figure A-10. Daily average of direction changes and mileage for regulation in Case 3A 



Figure A-11. Daily average of direction changes and mileage for load following in Case 3C
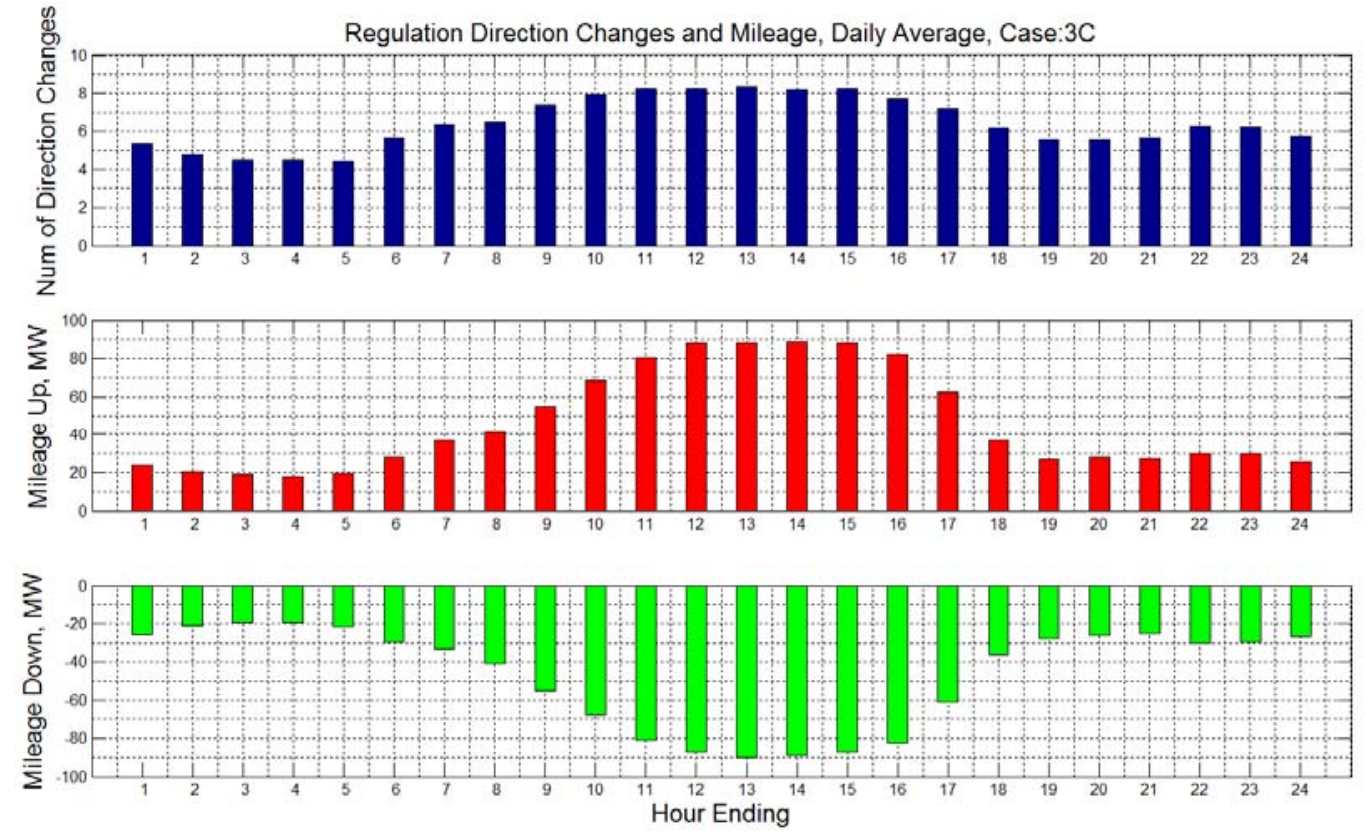

Figure A-12. Daily average of direction changes and mileage for regulation in Case 3C 

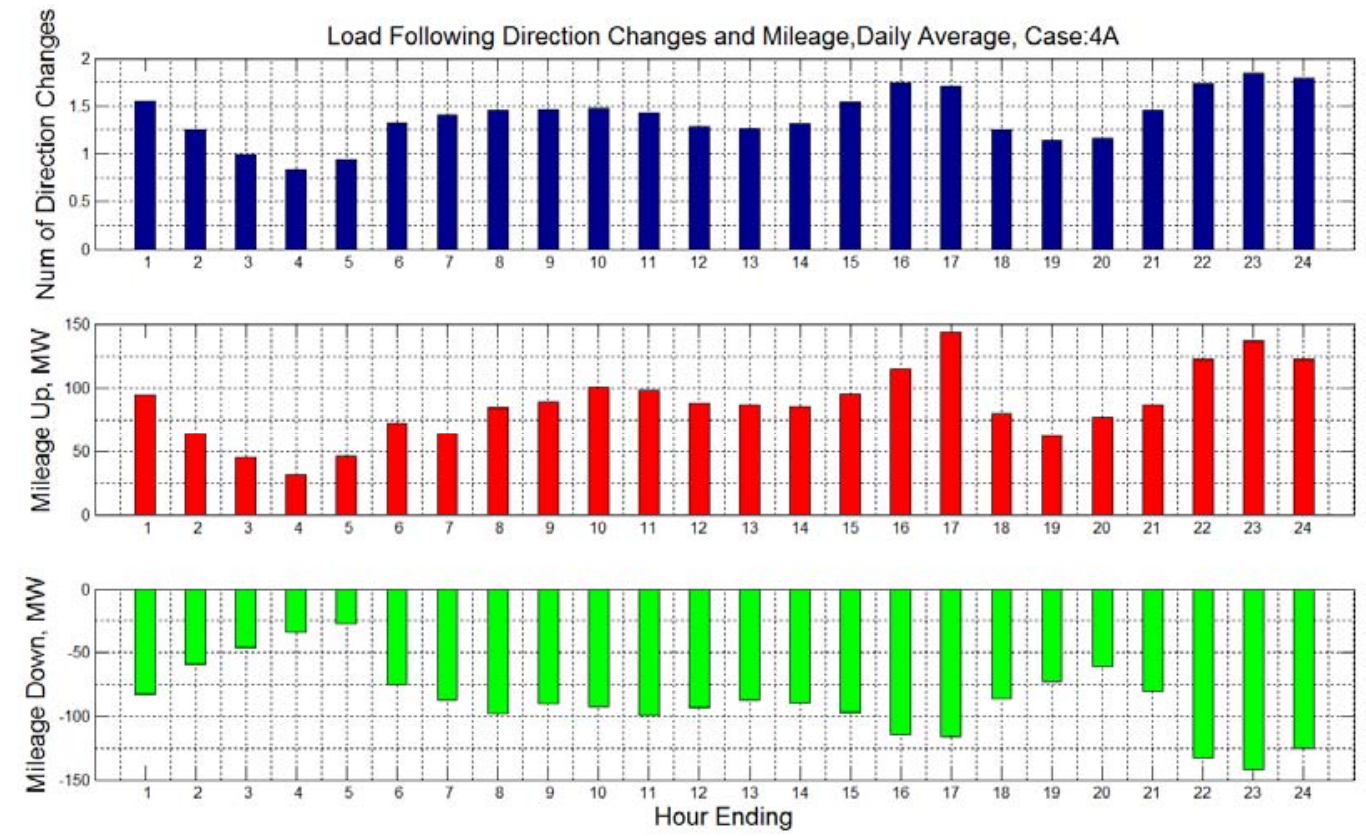

Figure A-13. Daily average of direction changes and mileage for load following in Case 4A


Figure A-14. Daily average of direction changes and mileage for regulation in Case 4A 



Figure A-15. Daily average of direction changes and mileage for load following in Case 4B
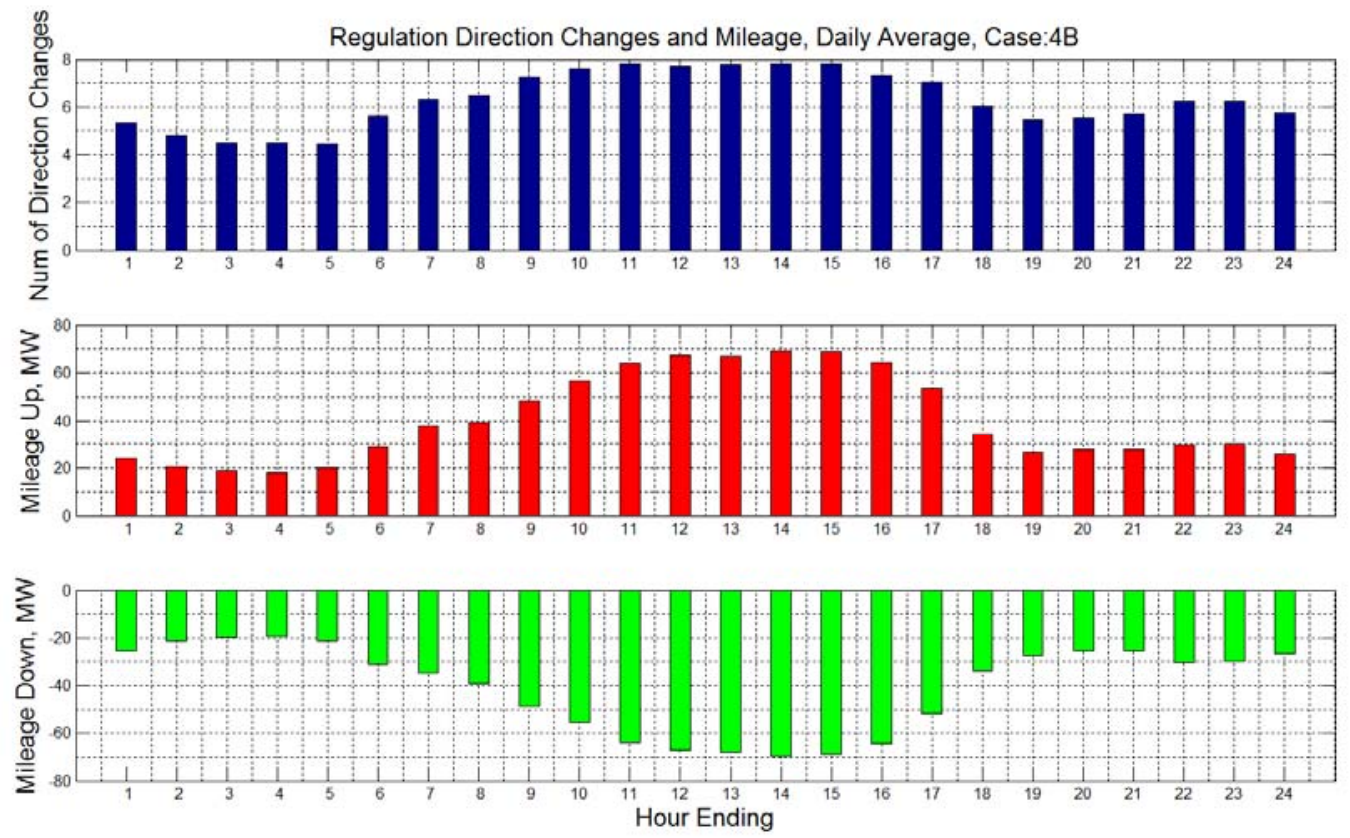

Figure A-16. Daily average of direction changes and mileage for regulation in Case 4B 


\section{APPENDIX B}

Ramp Statistics of Load Following and Regulation for Cases:

1A, 2A, 3A, 4A, 1B, 4B, 1C and 3C 


\section{Appendix B}

Table B-1. Load Following Half-cycle Analysis for Case 1A

\begin{tabular}{|c|c|c|c|c|c|c|c|c|c|c|c|c|c|}
\hline & & \multicolumn{12}{|c|}{ Load following half-cycle ramp rate in $\mathrm{MW} / \mathrm{min}$} \\
\hline \multirow{7}{*}{ 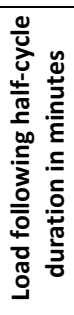 } & 0 & -55 & -45 & -35 & -25 & -15 & -5 & 5 & 15 & 25 & 35 & 45 & 55 \\
\hline & 10 & 0 & 0 & 0 & 0 & 13 & 177 & 146 & 9 & 0 & 0 & 0 & 0 \\
\hline & 30 & 1 & 1 & 4 & 31 & 385 & 2568 & 2971 & 345 & 6 & 1 & 1 & 1 \\
\hline & 50 & 0 & 0 & 0 & 0 & 0 & 1445 & 1176 & 0 & 0 & 0 & 0 & 0 \\
\hline & 70 & 0 & 0 & 0 & 0 & 0 & 259 & 246 & 0 & 0 & 0 & 0 & 0 \\
\hline & 90 & 0 & 0 & 0 & 0 & 0 & 254 & 247 & 1 & 0 & 0 & 0 & 0 \\
\hline & $>=110$ & 0 & 0 & 0 & 0 & 0 & 548 & 527 & 0 & 0 & 0 & 0 & 0 \\
\hline
\end{tabular}

Table B-2. Load Following Half-cycle Analysis for Case 2A

\begin{tabular}{|c|c|c|c|c|c|c|c|c|c|c|c|c|c|}
\hline & & \multicolumn{12}{|c|}{ Load following half-cycle ramp rate in $\mathrm{MW} / \mathrm{min}$} \\
\hline \multirow{7}{*}{ 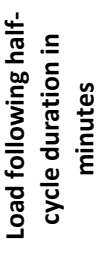 } & 0 & -55 & -45 & -35 & -25 & -15 & -5 & 5 & 15 & 25 & 35 & 45 & 55 \\
\hline & 10 & 0 & 0 & 0 & 0 & 12 & 200 & 162 & 7 & 0 & 0 & 0 & 0 \\
\hline & 30 & 1 & 1 & 4 & 31 & 398 & 2576 & 3037 & 350 & 6 & 1 & 1 & 1 \\
\hline & 50 & 0 & 0 & 0 & 0 & 0 & 1466 & 1160 & 0 & 0 & 0 & 0 & 0 \\
\hline & 70 & 0 & 0 & 0 & 0 & 0 & 255 & 261 & 0 & 0 & 0 & 0 & 0 \\
\hline & 90 & 0 & 0 & 0 & 0 & 0 & 250 & 235 & 1 & 0 & 0 & 0 & 0 \\
\hline & $>=110$ & 0 & 0 & 0 & 0 & 0 & 550 & 525 & 0 & 0 & 0 & 0 & 0 \\
\hline
\end{tabular}

Table B-3. Load Following Half-cycle Analysis for Case 3A

\begin{tabular}{|c|c|c|c|c|c|c|c|c|c|c|c|c|c|}
\hline & & \multicolumn{12}{|c|}{ Load following half-cycle ramp rate in $\mathrm{MW} / \mathrm{min}$} \\
\hline \multirow{7}{*}{ 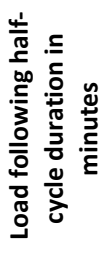 } & 0 & -55 & -45 & -35 & -25 & -15 & -5 & 5 & 15 & 25 & 35 & 45 & 55 \\
\hline & 10 & 0 & 0 & 0 & 0 & 14 & 258 & 201 & 7 & 0 & 0 & 0 & 0 \\
\hline & 30 & 1 & 1 & 5 & 31 & 393 & 2609 & 3113 & 348 & 6 & 1 & 1 & 1 \\
\hline & 50 & 0 & 0 & 0 & 0 & 0 & 1551 & 1227 & 0 & 0 & 0 & 0 & 0 \\
\hline & 70 & 0 & 0 & 0 & 0 & 0 & 249 & 265 & 0 & 0 & 0 & 0 & 0 \\
\hline & 90 & 0 & 0 & 0 & 0 & 0 & 245 & 221 & 1 & 0 & 0 & 0 & 0 \\
\hline & $>=110$ & 0 & 0 & 0 & 0 & 0 & 528 & 488 & 0 & 0 & 0 & 0 & 0 \\
\hline
\end{tabular}

Table B-4. Load Following Half-cycle Analysis for Case 4A

\begin{tabular}{|c|c|c|c|c|c|c|c|c|c|c|c|c|c|}
\hline & & \multicolumn{12}{|c|}{ Load following half-cycle ramp rate in $\mathrm{MW} / \mathrm{min}$} \\
\hline \multirow{7}{*}{ 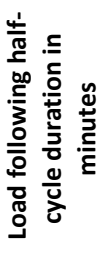 } & 0 & -55 & -45 & -35 & -25 & -15 & -5 & 5 & 15 & 25 & 35 & 45 & 55 \\
\hline & 10 & 0 & 0 & 0 & 0 & 38 & 320 & 226 & 14 & 0 & 0 & 0 & 0 \\
\hline & 30 & 1 & 1 & 6 & 29 & 420 & 2709 & 3332 & 351 & 6 & 1 & 1 & 1 \\
\hline & 50 & 0 & 0 & 0 & 0 & 0 & 1594 & 1234 & 0 & 0 & 0 & 0 & 0 \\
\hline & 70 & 0 & 0 & 0 & 0 & 0 & 252 & 270 & 0 & 0 & 0 & 0 & 0 \\
\hline & 90 & 0 & 0 & 0 & 0 & 0 & 250 & 222 & 1 & 0 & 0 & 0 & 0 \\
\hline & $>=110$ & 0 & 0 & 0 & 0 & 0 & 485 & 443 & 0 & 0 & 0 & 0 & 0 \\
\hline
\end{tabular}


Table B-5. Load Following Half-cycle Analysis for Case 1B

\begin{tabular}{|c|c|c|c|c|c|c|c|c|c|c|c|c|c|}
\hline & & \multicolumn{12}{|c|}{ Load following half-cycle ramp rate in $\mathrm{MW} / \mathrm{min}$} \\
\hline \multirow{7}{*}{ 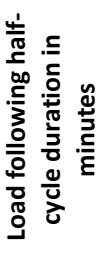 } & 0 & -55 & -45 & -35 & -25 & -15 & -5 & 5 & 15 & 25 & 35 & 45 & 55 \\
\hline & 10 & 0 & 0 & 0 & 0 & 41 & 376 & 336 & 28 & 0 & 0 & 0 & 0 \\
\hline & 30 & 1 & 1 & 8 & 33 & 481 & 2678 & 3276 & 368 & 6 & 1 & 1 & 1 \\
\hline & 50 & 0 & 0 & 0 & 0 & 2 & 1632 & 1239 & 1 & 0 & 0 & 0 & 0 \\
\hline & 70 & 0 & 0 & 0 & 0 & 0 & 225 & 303 & 0 & 0 & 0 & 0 & 0 \\
\hline & 90 & 0 & 0 & 0 & 0 & 0 & 242 & 208 & 1 & 0 & 0 & 0 & 0 \\
\hline & $>=110$ & 0 & 0 & 0 & 0 & 0 & 487 & 431 & 0 & 0 & 0 & 0 & 0 \\
\hline
\end{tabular}

Table B-6. Load Following Half-cycle Analysis for Case 4B

\begin{tabular}{|c|c|c|c|c|c|c|c|c|c|c|c|c|c|}
\hline & & \multicolumn{12}{|c|}{ Load following half-cycle ramp rate in $\mathrm{MW} / \mathrm{min}$} \\
\hline \multirow{7}{*}{  } & 0 & -55 & -45 & -35 & -25 & -15 & -5 & 5 & 15 & 25 & 35 & 45 & 55 \\
\hline & 10 & 0 & 0 & 0 & 2 & 77 & 467 & 387 & 40 & 0 & 0 & 0 & 0 \\
\hline & 30 & 1 & 1 & 10 & 39 & 589 & 2655 & 3444 & 475 & 7 & 2 & 1 & 1 \\
\hline & 50 & 0 & 0 & 0 & 0 & 4 & 1711 & 1267 & 18 & 0 & 0 & 0 & 0 \\
\hline & 70 & 0 & 0 & 0 & 0 & 0 & 228 & 264 & 0 & 0 & 0 & 0 & 0 \\
\hline & 90 & 0 & 0 & 0 & 0 & 0 & 230 & 189 & 1 & 0 & 0 & 0 & 0 \\
\hline & $>=110$ & 0 & 0 & 0 & 0 & 0 & 467 & 384 & 0 & 0 & 0 & 0 & 0 \\
\hline
\end{tabular}

Table B-7. Load Following Half-cycle Analysis for Case 1C

\begin{tabular}{|c|c|c|c|c|c|c|c|c|c|c|c|c|c|}
\hline & & \multicolumn{12}{|c|}{ Load following half-cycle ramp rate in $\mathrm{MW} / \mathrm{min}$} \\
\hline \multirow{7}{*}{ 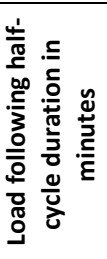 } & 0 & -55 & -45 & -35 & -25 & -15 & -5 & 5 & 15 & 25 & 35 & 45 & 55 \\
\hline & 10 & 0 & 0 & 0 & 3 & 115 & 471 & 439 & 75 & 1 & 0 & 0 & 0 \\
\hline & 30 & 1 & 2 & 9 & 48 & 617 & 2579 & 3385 & 482 & 12 & 2 & 1 & 1 \\
\hline & 50 & 0 & 0 & 0 & 1 & 11 & 1678 & 1212 & 11 & 0 & 0 & 0 & 0 \\
\hline & 70 & 0 & 0 & 0 & 0 & 2 & 215 & 278 & 3 & 0 & 0 & 0 & 0 \\
\hline & 90 & 0 & 0 & 0 & 0 & 0 & 231 & 179 & 1 & 0 & 0 & 0 & 0 \\
\hline & $>=110$ & 0 & 0 & 0 & 0 & 0 & 485 & 387 & 1 & 0 & 0 & 0 & 0 \\
\hline
\end{tabular}

Table B-8. Load Following Half-cycle Analysis for Case 3C

\begin{tabular}{|c|c|c|c|c|c|c|c|c|c|c|c|c|c|}
\hline & & \multicolumn{12}{|c|}{ Load following half-cycle ramp rate in $\mathrm{MW} / \mathrm{min}$} \\
\hline \multirow{7}{*}{ 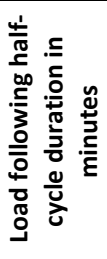 } & 0 & -55 & -45 & -35 & -25 & -15 & -5 & 5 & 15 & 25 & 35 & 45 & 55 \\
\hline & 10 & 0 & 0 & 0 & 5 & 131 & 500 & 445 & 93 & 2 & 0 & 0 & 0 \\
\hline & 30 & 1 & 2 & 9 & 52 & 673 & 2520 & 3407 & 541 & 15 & 3 & 1 & 1 \\
\hline & 50 & 0 & 0 & 0 & 0 & 11 & 1741 & 1210 & 23 & 0 & 0 & 0 & 0 \\
\hline & 70 & 0 & 0 & 0 & 0 & 2 & 225 & 275 & 3 & 0 & 0 & 0 & 0 \\
\hline & 90 & 0 & 0 & 0 & 0 & 0 & 219 & 184 & 0 & 0 & 0 & 0 & 0 \\
\hline & $>=110$ & 0 & 0 & 0 & 0 & 0 & 475 & 363 & 1 & 0 & 0 & 0 & 0 \\
\hline
\end{tabular}


Table B-9. Regulation Half-cycle Analysis for Case 1A

\begin{tabular}{|c|c|c|c|c|c|c|c|c|c|c|c|c|c|c|c|c|c|c|c|}
\hline \multirow{2}{*}{\multicolumn{2}{|c|}{$=$}} & \multicolumn{18}{|c|}{ Regulation half-cycle ramp rate in $\mathrm{MW} / \mathrm{min}$} \\
\hline \multirow{11}{*}{ 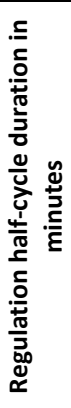 } & & -45 & -40 & -35 & -30 & -25 & -20 & -15 & -10 & -5 & 5 & 10 & 15 & 20 & 25 & 30 & 35 & 40 & 45 \\
\hline & 1 & 0 & 0 & 0 & 0 & 0 & 0 & 0 & 0 & 0 & 0 & 0 & 0 & 0 & 0 & 0 & 0 & 0 & 0 \\
\hline & 2 & 0 & 0 & 0 & 0 & 1 & 2 & 9 & 418 & 2364 & 2303 & 432 & 9 & 3 & 0 & 1 & 2 & 1 & 0 \\
\hline & 3 & 0 & 0 & 0 & 0 & 0 & 2 & 2 & 67 & 1502 & 1563 & 77 & 2 & 1 & 0 & 0 & 0 & 0 & 1 \\
\hline & $\overline{4}$ & 0 & 0 & 0 & 0 & 0 & 0 & 1 & 19 & 1034 & 982 & 26 & 2 & 0 & 1 & 0 & 0 & 0 & 0 \\
\hline & 5 & 0 & 0 & 0 & 0 & 0 & 1 & 0 & 6 & 561 & 578 & 5 & 0 & 1 & 0 & 0 & 0 & 0 & 0 \\
\hline & 6 & 0 & 0 & 0 & 0 & 0 & 0 & 0 & 0 & 337 & 334 & 1 & 0 & 0 & 0 & 0 & 0 & 0 & 0 \\
\hline & 7 & 0 & 0 & 0 & 0 & 0 & 1 & 0 & 0 & 179 & 180 & 1 & 1 & 0 & 0 & 0 & 0 & 0 & 0 \\
\hline & 8 & 0 & 0 & 0 & 0 & 0 & 0 & 0 & 2 & 95 & 94 & 1 & 0 & 0 & 0 & 0 & 0 & 0 & 0 \\
\hline & 9 & 0 & 0 & 0 & 0 & 0 & 0 & 0 & 0 & 55 & 63 & 1 & 0 & 0 & 0 & 0 & 0 & 0 & 0 \\
\hline & $>=10$ & 0 & 0 & 0 & 0 & 0 & 0 & 0 & 0 & 72 & 74 & 0 & 0 & 0 & 0 & 0 & 0 & 0 & 0 \\
\hline
\end{tabular}

Table B-10. Regulation Half-cycle Analysis for Case 2A

\begin{tabular}{|c|c|c|c|c|c|c|c|c|c|c|c|c|c|c|c|c|c|c|c|}
\hline \multirow{2}{*}{\multicolumn{2}{|c|}{$\sigma$}} & \multicolumn{18}{|c|}{ Regulation half-cycle ramp rate in $\mathrm{MW} / \mathrm{min}$} \\
\hline \multirow{11}{*}{ 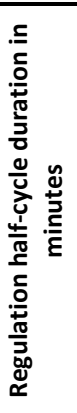 } & & -45 & -40 & -35 & -30 & -25 & -20 & -15 & -10 & -5 & 5 & 10 & 15 & 20 & 25 & 30 & 35 & 40 & 45 \\
\hline & $\overline{1}$ & 0 & 0 & 0 & 0 & $\overline{0}$ & 0 & 0 & 0 & 0 & 0 & 0 & 0 & 0 & 0 & 0 & 0 & 0 & $\overline{0}$ \\
\hline & 2 & 1 & 0 & 0 & 0 & 1 & 2 & 10 & 436 & 2390 & 2288 & 448 & 10 & 3 & 0 & 1 & 2 & 1 & 0 \\
\hline & 3 & 0 & 0 & 0 & 0 & 0 & 2 & 4 & 94 & 1548 & 1612 & 86 & 2 & 1 & 0 & 0 & 0 & 0 & 1 \\
\hline & 4 & 0 & 0 & 0 & 0 & 0 & 0 & 1 & 23 & 1108 & 1023 & 30 & 4 & 0 & 1 & 0 & 0 & 0 & 0 \\
\hline & 5 & 0 & 0 & 0 & 0 & 0 & 0 & 1 & 11 & 643 & 640 & 10 & 0 & 1 & 0 & 0 & 0 & 0 & 0 \\
\hline & 6 & 0 & 0 & 0 & 0 & 0 & 0 & 0 & 0 & 374 & 353 & 5 & 0 & 0 & 0 & 0 & 0 & 0 & 0 \\
\hline & 7 & 0 & 0 & 0 & 0 & 0 & 1 & 0 & 0 & 196 & 222 & 2 & 1 & 0 & 0 & 0 & 0 & 0 & 0 \\
\hline & 8 & 0 & 0 & 0 & 0 & 0 & 0 & 0 & 2 & 113 & 121 & 1 & 0 & 0 & 0 & 0 & 0 & 0 & 0 \\
\hline & 9 & 0 & 0 & 0 & 0 & 0 & 0 & 0 & 0 & 83 & 77 & 1 & 0 & 0 & 0 & 0 & 0 & 0 & 0 \\
\hline & $>=10$ & 0 & 0 & 0 & 0 & 0 & 0 & 0 & 0 & 93 & 80 & 1 & 0 & 0 & 0 & 0 & 0 & 0 & 0 \\
\hline
\end{tabular}

Table B-11. Regulation Half-cycle Analysis for Case 3A

\begin{tabular}{|c|c|c|c|c|c|c|c|c|c|c|c|c|c|c|c|c|c|c|c|}
\hline \multirow{2}{*}{\multicolumn{2}{|c|}{$\varepsilon$}} & \multicolumn{18}{|c|}{ Regulation half-cycle ramp rate in $\mathrm{MW} / \mathrm{min}$} \\
\hline \multirow{11}{*}{ 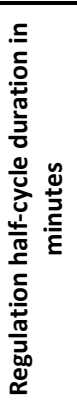 } & & -45 & -40 & -35 & -30 & -25 & -20 & -15 & -10 & -5 & 5 & 10 & 15 & 20 & 25 & 30 & 35 & 40 & 45 \\
\hline & 1 & 0 & 0 & 0 & 0 & 0 & 0 & 0 & 0 & 0 & 0 & 0 & 0 & 0 & 0 & 0 & 0 & 0 & 0 \\
\hline & 2 & 0 & 0 & 0 & 0 & 2 & 2 & 17 & 439 & 2367 & 2294 & 471 & 16 & 3 & 0 & 1 & 2 & 1 & 0 \\
\hline & 3 & 0 & 0 & 0 & 0 & 1 & 5 & 14 & 120 & 1585 & 1632 & 110 & 27 & 3 & 2 & 0 & 0 & 0 & 1 \\
\hline & 4 & 0 & 0 & 0 & 0 & 0 & 1 & 5 & 70 & 1131 & 1042 & 59 & 8 & 0 & 1 & 0 & 0 & 0 & 0 \\
\hline & 5 & 0 & 0 & 0 & 0 & 0 & 1 & 2 & 38 & 679 & 678 & 28 & 3 & 1 & 0 & 0 & 0 & 0 & 0 \\
\hline & 6 & 0 & 0 & 0 & 0 & 0 & 0 & 0 & 8 & 425 & 409 & 19 & 1 & 0 & 0 & 0 & 0 & 0 & 0 \\
\hline & 7 & 0 & 0 & 0 & 0 & 0 & 1 & 0 & 8 & 248 & 275 & 8 & 1 & 0 & 0 & 0 & 0 & 0 & 0 \\
\hline & 8 & 0 & 0 & 0 & 0 & 0 & 0 & 0 & 7 & 174 & 149 & 7 & 0 & 0 & 0 & 0 & 0 & 0 & 0 \\
\hline & 9 & 0 & 0 & 0 & 0 & 0 & 0 & 0 & 2 & 98 & 108 & 5 & 0 & 0 & 0 & 0 & 0 & 0 & 0 \\
\hline & $>=10$ & 0 & 0 & 0 & 0 & 0 & 0 & 0 & 2 & 156 & 145 & 1 & 0 & 0 & 0 & 0 & 0 & 0 & 0 \\
\hline
\end{tabular}

Table B-12. Regulation Half-cycle Analysis for Case 4A

\begin{tabular}{|c|c|c|c|c|c|c|c|c|c|c|c|c|c|c|c|c|c|c|c|}
\hline & & \multicolumn{18}{|c|}{ Regulation half-cycle ramp rate in $\mathrm{MW} / \mathrm{min}$} \\
\hline \multirow{11}{*}{ 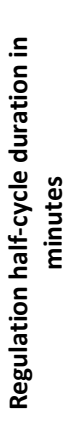 } & 0 & -45 & -40 & -35 & -30 & -25 & -20 & -15 & -10 & -5 & 5 & 10 & 15 & 20 & 25 & 30 & 35 & 40 & 45 \\
\hline & 1 & 0 & 0 & 0 & 0 & 0 & 0 & 0 & 0 & 0 & 0 & 0 & 0 & 0 & 0 & 0 & 0 & 0 & 0 \\
\hline & 2 & 1 & 0 & 0 & 0 & 1 & 4 & 14 & 464 & 2411 & 2340 & 494 & 12 & 5 & 0 & 1 & 2 & 1 & 0 \\
\hline & 3 & 0 & 0 & 0 & 0 & 0 & 1 & 9 & 104 & 1640 & 1666 & 121 & 12 & 3 & 0 & 0 & 0 & 0 & 1 \\
\hline & 4 & 0 & 0 & 0 & 0 & 0 & 2 & 8 & 57 & 1110 & 1072 & 63 & 7 & 1 & 1 & 0 & 0 & 0 & 0 \\
\hline & 5 & 0 & 0 & 0 & 0 & 0 & 0 & 5 & 29 & 742 & 733 & 49 & 3 & 1 & 0 & 0 & 0 & 0 & 0 \\
\hline & 6 & 0 & 0 & 0 & 0 & 0 & 0 & 3 & 15 & 471 & 414 & 22 & 2 & 0 & 0 & 0 & 0 & 0 & 0 \\
\hline & 7 & 0 & 0 & 0 & 0 & 0 & 1 & 1 & 8 & 276 & 313 & 13 & 2 & 0 & 0 & 0 & 0 & 0 & 0 \\
\hline & 8 & 0 & 0 & 0 & 0 & 0 & 0 & 0 & 4 & 192 & 173 & 4 & 0 & 0 & 0 & 0 & 0 & 0 & 0 \\
\hline & 9 & 0 & 0 & 0 & 0 & 0 & 0 & 0 & 3 & 118 & 123 & 4 & 1 & 0 & 0 & 0 & 0 & 0 & 0 \\
\hline & $>=10$ & 0 & 0 & 0 & 0 & 0 & 0 & 0 & 3 & 195 & 196 & 3 & 0 & 0 & 0 & 0 & 0 & 0 & 0 \\
\hline
\end{tabular}


Table B-13. Regulation Half-cycle Analysis for Case 1B

\begin{tabular}{|c|c|c|c|c|c|c|c|c|c|c|c|c|c|c|c|c|c|c|c|}
\hline & \multicolumn{18}{|c|}{ Regulation half-cycle ramp rate in $\mathrm{MW} / \mathrm{min}$} \\
\hline \multirow{11}{*}{ 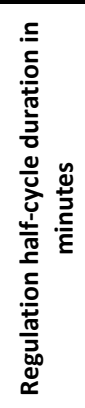 } & & -45 & -40 & -35 & -30 & -25 & -20 & -15 & -10 & -5 & 5 & 10 & 15 & 20 & 25 & 30 & 35 & 40 & 45 \\
\hline & 1 & 0 & 0 & 0 & 0 & 0 & 0 & 0 & 0 & 0 & 0 & 0 & 0 & 0 & 0 & 0 & 0 & 0 & 0 \\
\hline & 2 & 0 & 0 & 0 & 0 & 2 & 4 & 16 & 475 & 2428 & 2416 & 478 & 17 & 5 & 2 & 1 & 2 & 1 & 0 \\
\hline & 3 & 0 & 0 & 1 & 0 & 0 & 3 & 12 & 127 & 1579 & 1686 & 130 & 12 & 3 & 1 & 0 & 0 & 0 & 1 \\
\hline & 4 & 0 & 0 & 0 & 0 & 0 & 3 & 10 & 74 & 1136 & 1068 & 79 & 13 & 2 & 1 & 0 & 0 & 0 & 0 \\
\hline & 5 & 0 & 0 & 0 & 0 & 0 & 1 & 5 & 53 & 704 & 709 & 37 & 5 & 0 & 0 & 0 & 0 & 0 & 0 \\
\hline & 6 & 0 & 0 & 0 & 0 & 0 & 1 & 8 & 42 & 472 & 439 & 2 & 2 & 0 & 0 & 0 & 0 & 0 & 0 \\
\hline & 7 & 0 & 0 & 0 & 0 & 0 & 3 & 3 & 26 & 284 & 331 & 20 & 3 & 2 & 0 & 0 & 0 & 0 & 0 \\
\hline & 8 & 0 & 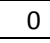 & 0 & 0 & 0 & 0 & 4 & 22 & 223 & 211 & 29 & 5 & 0 & 0 & 0 & 0 & 0 & 0 \\
\hline & 9 & 0 & 0 & 0 &  & 0 & 0 & 3 & 17 & 186 & 199 & 16 & 2 & 1 & 0 & 0 & 0 & 0 & 0 \\
\hline & $>=10$ & 0 & 0 & 0 & 0 & 0 & 0 & 0 & 20 & 404 & 387 & 37 & 2 & 0 & 0 & 0 & 0 & 0 & 0 \\
\hline
\end{tabular}

Table B-14. Regulation Half-cycle Analysis for Case 4B

\begin{tabular}{|c|c|c|c|c|c|c|c|c|c|c|c|c|c|c|c|c|c|c|c|}
\hline & \multicolumn{18}{|c|}{ Regulation half-cycle ramp rate in $\mathrm{MW} / \mathrm{min}$} \\
\hline \multirow{11}{*}{ 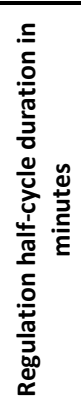 } & 0 & -45 & -40 & -35 & -30 & -25 & -20 & -15 & -10 & -5 & 5 & 10 & 15 & 20 & 25 & 30 & 35 & 40 & 45 \\
\hline & 1 & 0 & 0 & 0 & 0 & 0 & 0 & 0 & 0 & 0 & $\overline{0}$ & 0 & 0 & 0 & 0 & 0 & 0 & 0 & 0 \\
\hline & 2 & 0 & 0 & 0 & 2 & 1 & 6 & 15 & 528 & 2448 & 2389 & 547 & 21 & 8 & 1 & 1 & 2 & 1 & 0 \\
\hline & 3 & 0 & 0 & 0 & 0 & 0 & 3 & 22 & 164 & 1675 & 1770 & 169 & 25 & 6 & 1 & 1 & 0 & 0 & 1 \\
\hline & 4 & 0 & 0 & 0 & 0 & 1 & 3 & 18 & 113 & 1169 & 1138 & 114 & 23 & 2 & 1 & 0 & 0 & 0 & 0 \\
\hline & 5 & 0 & 0 & 0 & 0 & 0 & 5 & 13 & 82 & 825 & 835 & 84 & 12 & 3 & 0 & 0 & 0 & 0 & 0 \\
\hline & 6 & 0 & 0 & 0 & 0 & 0 & 1 & 9 & 61 & 563 & 502 & 49 & 8 & 0 & 0 & 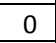 & 0 & 0 & 0 \\
\hline & 7 & 0 & 0 & 0 & 0 & 0 & 3 & 9 & 35 & 340 & 392 & 39 & 6 & 0 & 0 & 0 & 0 & 0 & 0 \\
\hline & 8 & 0 & 0 & 0 & 0 & 0 & 1 & 4 & 24 & 280 & 260 & 34 & 10 & 0 & 0 & 0 & 0 & 0 & 0 \\
\hline & 9 & 0 & 0 & 0 & 0 & 0 & 0 & 4 & 21 & 220 & 219 & 22 & 5 & 0 & 0 & 0 & 0 & 0 & 0 \\
\hline & $>=10$ & 0 & 0 & 0 & 0 & 0 & 0 & 4 & 29 & 480 & 463 & 38 & 5 & 0 & 0 & 0 & 0 & 0 & 0 \\
\hline
\end{tabular}

Table B-15. Regulation Half-cycle Analysis for Case 1C

\begin{tabular}{|c|c|c|c|c|c|c|c|c|c|c|c|c|c|c|c|c|c|c|c|}
\hline & \multicolumn{18}{|c|}{ Regulation half-cycle ramp rate in $\mathrm{MW} / \mathrm{min}$} \\
\hline \multirow{11}{*}{ 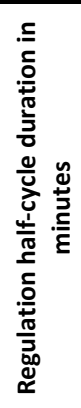 } & 0 & -45 & -40 & -35 & -30 & -25 & -20 & -15 & -10 & -5 & 5 & 10 & 15 & 20 & 25 & 30 & 35 & 40 & 45 \\
\hline & 1 & 0 & 0 & 0 & 0 & 0 & $\Omega$ & 0 & 0 & 0 & 0 & 0 & 0 & 0 & 0 & 0 & 0 & 0 & 0 \\
\hline & 2 & 2 & 0 & 0 & 1 & 2 & 7 & 25 & 555 & 2464 & 2429 & 558 & 34 & 9 & 2 & 1 & 3 & 2 & 0 \\
\hline & 3 & $\underline{0}$ & 0 & 1 & 4 & 3 & 15 & 44 & 198 & 1613 & 1725 & 228 & 36 & 11 & 9 & 0 & 1 & 2 & 1 \\
\hline & 4 & 0 & 0 & $\underline{0}$ & 3 & 2 & 15 & 37 & 129 & 1175 & 1096 & 120 & 42 & 13 & 7 & 1 & 0 & 0 & 0 \\
\hline & 5 & 0 & 0 & 0 & 1 & 4 & 3 & 32 & 111 & 755 & 726 & 96 & 28 & 6 & 4 & 0 & 0 & 0 & 0 \\
\hline & 6 & 0 & 0 & 0 & 0 & 2 & 6 & 24 & 74 & 516 & 498 & 70 & 13 & 3 & 4 & 0 & 1 & 0 & 0 \\
\hline & 7 & 0 & 0 & 0 & & 4 & 8 & 21 & 65 & 300 & 343 & s & 15 & 6 & 0 & 0 & 0 & 0 & $\underline{0}$ \\
\hline & 8 & 0 & 0 & 0 & $\underline{0}$ & 2 & 4 & 7 & 35 & 227 & 251 & 59 & 17 & 6 & 4 & 0 & 0 & 0 & $\underline{0}$ \\
\hline & $\overline{9}$ & 0 & 0 & $\underline{0}$ & $\underline{0}$ & 1 & 4 & 17 & 38 & 225 & 227 & 37 & 7 & 3 & 2 & 1 & 0 & 0 & $\underline{0}$ \\
\hline & $>=10$ & 0 & 0 & 0 & 0 & 1 & 3 & 19 & 85 & 510 & 485 & 86 & 32 & 4 & 2 & 0 & 0 & 0 & 0 \\
\hline
\end{tabular}

Table B-16. Regulation Half-cycle Analysis for Case 3C

\begin{tabular}{|c|c|c|c|c|c|c|c|c|c|c|c|c|c|c|c|c|c|c|c|}
\hline \multirow{2}{*}{\multicolumn{2}{|c|}{0}} & \multicolumn{18}{|c|}{ Regulation half-cycle ramp rate in $\mathrm{MW} / \mathrm{min}$} \\
\hline & & -45 & -40 & -35 & -30 & 25 & -20 & -15 & -10 & -5 & 5 & 10 & \begin{tabular}{|l|}
15 \\
\end{tabular} & 20 & 25 & 30 & 35 & \begin{tabular}{|l|}
40 \\
\end{tabular} & 45 \\
\hline \multirow{10}{*}{ 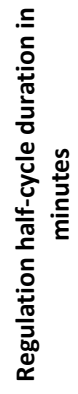 } & 1 & $\overline{0}$ & $\overline{0}$ & 0 & 0 & 0 & $\overline{0}$ & 0 & $\overline{0}$ & 0 & 0 & 0 & 0 & 0 & 0 & 0 & 0 & 0 & $\overline{0}$ \\
\hline & 2 & 2 & 0 & 0 & 2 & 3 & 9 & 29 & 598 & 2480 & 2436 & 607 & \begin{tabular}{|l|}
39 \\
\end{tabular} & 8 & 3 & 1 & 3 & 1 & U \\
\hline & 3 & 0 & 0 & 1 & 3 & 5 & 15 & 50 & 227 & 1675 & 1719 & 252 & 48 & 15 & 6 & 4 & 1 & 0 & 1 \\
\hline & 4 & 0 & 0 & 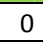 & 3 & 4 & 18 & 43 & 170 & 1240 & 1132 & 181 & 43 & 21 & 4 & 7 & 1 & 0 & $\underline{0}$ \\
\hline & 5 & 0 & 0 & 0 & 2 & 2 & 13 & 37 & 136 & 820 & 781 & 114 & 28 & 9 & 5 & 1 & 0 & $\begin{array}{ll}0 \\
\end{array}$ & 0 \\
\hline & $\overline{6}$ & 0 & 0 & 0 & 0 & 2 & 13 & 21 & 84 & 541 & 545 & 92 & 20 & 4 & 3 & 0 & 0 & 0 & $\underline{0}$ \\
\hline & 7 & 0 & 0 & 0 & 3 & 2 & 9 & 17 & 67 & 375 & 422 & 79 & 14 & 4 & 0 & 0 & 0 & \begin{tabular}{l|l}
0 \\
\end{tabular} & 0 \\
\hline & 8 & 0 & 0 & U & 0 & 1 & 4 & 15 & 52 & 283 & 297 & 64 & 18 & 11 & 1 & 0 & 0 & $\begin{array}{ll}0 \\
\end{array}$ & 0 \\
\hline & 9 & $\underline{0}$ & 0 & 0 & 0 & 2 & 2 & 19 & 43 & 233 & 231 & 36 & 12 & 4 & 2 & 1 & 0 & 0 & $\underline{0}$ \\
\hline & $>=10$ & 0 & 0 & 0 & 0 & 1 & 3 & 18 & 83 & 552 & 528 & 81 & 32 & 5 & 3 & 0 & 0 & $\begin{array}{ll}0 \\
\end{array}$ & 0 \\
\hline
\end{tabular}


PNNL-20594

\section{Distribution}

No. of

Copies

\# Name

Organization

Address

City, State, ZIP Code
No. of

Copies 


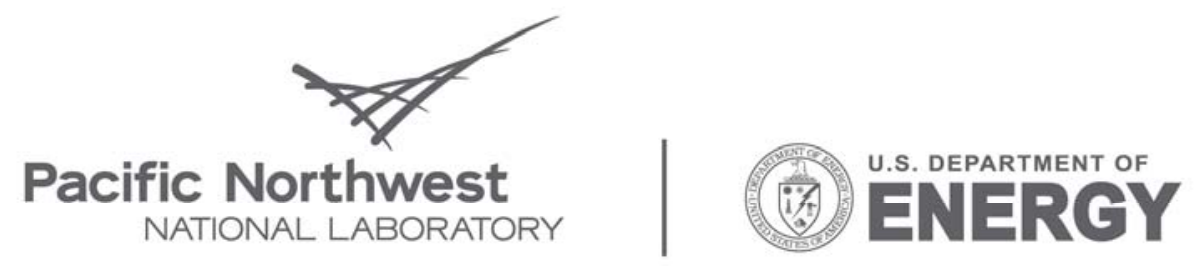

Proudly Operated by Battelle Since 1965

902 Battelle Boulevard

P.O. Box 999

Richland, WA 99352

1-888-375-PNNL (7665)

www.pnl.gov 